\title{
GASTROMEGALY AND CHRONIC DUODENAL ILEUS IN CHILDREN \\ BY
}

\author{
REGINALD MILLER, M.D., F.R.C.P., \\ Physician, Paddington Green Children's Hospital, \\ with \\ H. COURTNEY GAGE, L.R.C.P., M.R.C.S., \\ Radiologist, St. Mary's Hospital, London.
}

This paper is concerned with a series of nine children who exhibited enlargement of the stomach with visible gastric peristalsis or other signs of obstruction high in the alimentary tract. The similarity between the cases is sufficient to suggest that they all belong to one group originating in some form of duodenal obstruction. Two of the nine cases were submitted to operation and were found to be examples of chronic duodenal ileus, and it is suggested that the others of the series owe their origin to the same cause.

Gastromegaly is a convenient term for the enlarged and hypertrophied stomach which is the most striking clinical feature of such cases as these. Such a condition implies obstruction to the evacuation of the stomach and may be due to various causes; and as the site and nature of the obstruction, and even its very presence, may be difficult to determine, it is useful to have a group name which covers all such cases and emphasizes their one most obvious clinical abnormality. Were, for instance, the diagnosis of chronic duodenal ileus in the present cases disputed (and the subject is one of great difficulty), they would remain as a type of gastromegaly of obscure origin.

Duodenal ileus and arterio-mesenteric occlusion of the duodenum are the terms given to the condition in which the duodenum is compressed by the root of the mesentery and (usually) the superior mesenteric artery, as they lie over the duodeno-jejunal flexure. Both acute and chronic duodenal ileus are well recognized conditions in adults. This paper is concerned only with the chronic type, and as it occurs in children.

\section{DUODENAL ILEUS IN ADULTS.}

There is a considerable literature dealing with duodenal ileus in adults, and since the beginning of the present century the condition seems to have bean almost universally recognized.

Credit is usually given to Rokitansky ${ }^{1}$ as being the first to recognize the possibility of compression of the bowel by the root of the mesentery. This was in 1842 , and in $1863^{2}$ he described compression of the duodenum by the superior mesenteric artery as occurring in elderly people with visceroptosis. Heschl $^{3}$ (1855) and Glénard 4, 5 (1885 and 1889) were prominent writers on the subject. Clinically acute duodenal ileus, usually post-operative, first attracted 
attention, and in $1891 \mathrm{Kundrat}^{6}$ reported three such cases. Others, mainly isolated examples, were reported in Ciermany and England. Presently it was noted that in some instances, in spite of the fact that the final symptoms were acute in onset and of short duration, hypertrophy of the stomach and duodenum was present; and this led to the description of chronic duodenal ileus. By 1899 Albrecht $^{7}$ was able to collect many cases and write a very full account of the condition, describing both acute and chronic types, and giving details of treatment by posture, lavage and gastro-enterostomy.

In France, according to Duval, chronic duodenal ileus was first described by Petit ${ }^{8}$ in his thesis ' On the strangulation of the duodenum at the level of the mesenteric root' (1900). Many papers on the subject have appeared in the French literature, and special mention must be made of the chapter on the condition in the book 'The Duodenum' by Duval, Roux and Béclère 9 .

In America duodenal ileus has also attracted much attention since 1900. Amongst those who early interested themselves in the subject must be mentioned Robinson ${ }^{10},{ }^{11}$ (1900), Finney ${ }^{12}$ (1906), Barker ${ }^{13}$ (1906), Bloodgood ${ }^{14}$ (1907), and Staveley ${ }^{15}$ (1908). In 1911 and 1912 there appeared further communications by Staveley ${ }^{16}$ and Bloodgood ${ }^{17}$. In 1921 the Kelloggs ${ }^{18}$ reported a series of 41 cases all submitted to operation, and in 1926 Higgins $^{19}$ published 56 personal cases. The treatment of chronic duodenal ileus by duodeno-jejunostomy is said to have been first suggested by Barker ${ }^{13}$ and Bloodgood ${ }^{14}$, and the operation first performed by Staveley ${ }^{15}$.

In England, although acute arterio-mesenteric ileus became a recognized entity, practically no attention was paid to chronic duodenal ileus until the publication by Wilkie ${ }^{20}$ of his first paper on the subjeçt in 1921, and this with his two subsequent communications ${ }^{21,}{ }^{22}$,still remain the chief contributions to the study of chronic duodenal ileus in the English literature.

The subject of chronic duodenal ileus in adults has excited much discussion, particularly over the two points of its frequency and pathogenesis.

As regards the first point, those who have specially interested themselves in the condition are inclined to lay stress upon its comparative frequency; but the general English surgical opinion at the present time seems to be that, although chronic duodenal ileus has won for itself full recognition, it remains a rarity, and that its frequency can easily be exaggerated even after inspection of the parts at operation.

The explanation of the mechanism by which obstructive symptoms are produced in chronic duodenal ileus forms rather a difficult and complicated problem. It is thought, in the first place, that there must be a congenital factor, an abnormal anatomical development, constricting the space through which the duodenum passes under the mesenteric pedicle and the superior mesenteric artery. The relative importance of this factor has been much debated. If it does not operate it is difficult to see why obstructive symptoms of duodenal ileus should arise in later life in some cases of visceroptosis and not in others: while, on the other hand, if the congenital factor is of real importance, it is, as several writers have argued, difficult to understand why the condition is so little known amongst children. A consideration of chronic duodenal ileus in children may be expected to throw an interesting light on this particular point, and it is gratifying to feel that the cases here recorded supply, as it were, a long-felt want.

It is thought that in adult cases this congenital anatomical factor at the most predisposes to the development of obstructive symptoms in later life, and is not of itself sufficient to cause these symptoms until additional and accessory factors come into play. These, by dragging on the mesentery 
and so further reducing the space through which the duodenum passes, lead to actual compression of the bowel. These accessory factors concern the stomach, small intestine and colon. Visceroptosis is regarded as the commonest of them, and this accounts for the age incidence of chronic duodenal ileus and its greater frequency in women than in men. Distension, overloading and sagging of the proximal colon are the causes in another group of cases. Here the colon, by congenital formation, may be unduly mobile, and the artery traversing the duodenum may be the right colic and not the superior mesenteric artery. Glénard ${ }^{5}$, Barton ${ }^{23}$ and others regard ptosis, atony and dilatation of the stomach as able to lead to compression of the duodenum in a third group of cases. Distension of the stomach by air-swallowing has been put forward by Leveuf ${ }^{4}$ as a possible factor. On this point Wilkie ${ }^{20}$ expresses the view that air-swallowing may aggravate the condition but is not of primary ætiological significance.

In another group of cases which are rather different from the foregoing, in that no congenital factor need be postulated, disease of the mesentery or its glands produces direct compression of the duodenum. Tuberculosis and malignant disease have been reported as the agents responsible for such cases by Grégoire ${ }^{25}$ and Wilkie ${ }^{22}$.

Acute arterio-mesenteric ileus accounts for at least some of the cases described as 'acute dilatation of the stomach,' 'gastrorrhoea' and 'acute paralytic distension of the stomach,' which occur most commonly after laparotomy. As has been already mentioned, in some of the examples of this acute condition, hypertrophy of the stomach and duodenum has been recognized, and it is therefore supposed that many of them owe their origin to chronic duodenal ileus which has either been symptomless or undiagnosed. Wilkie:0 has expressed the opinion that 'acute dilatation of the stomach, either idioor post-operative, is probably a gross manifestation of a previously present chronic condition.'

\section{DUODENAL ILEUS IN CHILDREN.}

The amount of attention which has been paid to duodenal ileus in children is scanty, and there is no paper in the literature devoted to a consideration of the subject. On the other hand there are some isolated references to it, and an attempt is made here to summarize these so as to give some idea of the present position of affairs with regard to this condition. No cases altogether similar to the series reported here seem to have been published hitherto.

Acute ileus.-Acute duodenal ileus of the type seen in adults does not seem to occur in children. There is no mention of it in the literature, and surgeons of great experience in pædiatrics do not seem to have met it. Although this paper is concerned only with the chronic type of duodenal ileus, it is proper to mention the non-occurrence of the acute cases. As the acute type is thought to be predisposed to by preceding chronic compression, its absence in children might be taken as evidence against the occurrence of chronic cases in them. But the evidence in favour of their occurrence is far stronger, and probably the absence of the acute cases is due to the fact that severe atony and ptosis of the obstructed stomach are unlikely to occur in children. 
Chronic ileus.-Chronic duodenal ileus in children has been described in isolated examples; but before passing to these and the groups into which they fall, there are two points bearing on the question which must be mentioned.

One has already received attention, namely, the question raised in discussing the pathogenesis of chronic duodenal ileus, why so little is known of the condition in children. This point has been pressed, for example, by Gracie $^{26}$, and the significance of the argument has been explained earlier in this paper.

The second point is of greater interest and consists in the fact that a proportion of cases operated on for chronic duodenal ileus in adult life give histories of attacks of vomiting in early life. This observation, which clearly has an important bearing on the present subject, was made by Wilkie ${ }^{22}$ in 1927 and has recently been confirmed by Hayes and Shaw ${ }^{27}$. On this point Wilkie ${ }^{2 \cdot 2}$ has written :-

Not infrequently these attacks (of bilious vomiting) date back to early childhood and are regarded as constitutional or as evidence of recurring acidosis. Such attacks may disappear during late adolescence and the patient may enjoy comfort for ten or fifteen years, when there appear the flatulent symptoms which bring the patient to seek relief. This late reappearance of symptoms may follow child-bearing, some illness, such as influenza, or periods of mental worry associated with deficient muscular exercise and fresh air, in fact with any condition which tends to lower the tone of the abdominal muscles and to favour visceroptosis.

No detailed description of these cases in their childhood has been given. In view of this observation it is of interest that the series of cases to be reported in this paper has shown instances in which spontaneous improvement was taking place. In this respect they differ from any other cases of chronic duodenal ileus in children as yet reported, and it is difficult not to conclude that the present cases are of the type referred to by Wilkie, but diagnosed during childhood. If this assumption is correct, an important matter in ultimate prognosis is involved.

Passing to the published cases of chronic duodenal ileus in children, these are found to fall into two main groups, neither of which is altogether similar to the present series of cases. It is sufficient here to give a general description of the types of these recorded cases : synopses of the case reports will be found in Appendix B.

Group 1. Cases with megaduodenum. This group consists of rare cases, usually in very early life, in which the arterio-mesenteric compression is severe enough to produce great enlargement of the duodenum. In them the duodenum is found as a visible and palpable tumour, and may even show peristalsis. In some instances it is described as the size of a second stomach, and skiagrams easily demonstrate the enlarged duodenum extending beyond the enlarged stomach. The symptoms are severe, and consist of vomiting and its consequences. Such cases are to some extent comparable clinically with hypertrophic pyloric stenosis, from which they are distinguished by the 
absence of a pyloric tumour, the presence of bile in the vomitus, and the signs of megaduodenum. They may also be simulated by congenital duodenal stenosis. The presence of some form of obstruction is apparently obvious from the severity of the vomiting. Some cases have been successfully treated by duodeno-jejunostomy. They show no tendency towards spontaneous improvement.

The first of these cases was reported by Bernheim-Karrer ${ }^{28}$ in 1904, and since then further examples have been published by Frank ${ }^{29}$, Downes ${ }^{30}$, DuBose ${ }^{31}$, Jewesbury ${ }^{32}$, and Henske and Best $^{33}$ (see Table 1 and Appendix B). Megaduodenum may be due to other causes than arterio-mesenteric compression. Many cases have been recorded as due to obstruction by peritoneal bands, a class of case recently reviewed by Higgins and Paterson ${ }^{34}$. It has also been recorded as due to congenital duodenal stenosis by Jewesbury ${ }^{32}$, and by Variot and Cailliau ${ }^{35}$; and to pressure from a tumour on the duodenum in a new born infant by Hohlbaum ${ }^{36}$.

TABLE 1.

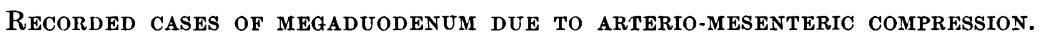

\begin{tabular}{|c|c|c|c|c|c|c|c|c|c|}
\hline \multirow[t]{2}{*}{ Author. } & \multirow[t]{2}{*}{ Date. } & \multirow[t]{2}{*}{ Sex. } & \multirow{2}{*}{$\begin{array}{c}\text { Age of } \\
\text { onset of } \\
\text { symptoms. }\end{array}$} & \multirow{2}{*}{$\begin{array}{l}\text { Age when } \\
\text { first seen. }\end{array}$} & \multicolumn{4}{|c|}{ Enlargement of duodenum. } & \multirow[t]{2}{*}{ Result. } \\
\hline & & & & & Clinical. & $\mathrm{X}$-ray. & Autopsy. & Operation. & \\
\hline $\begin{array}{l}\text { Bernheim- } \\
\text { Karrer28 }\end{array}$ & 1.904 & $\mathbf{M}$ & Birth & 8 months & & & $\begin{array}{l}\text { Greatly } \\
\text { dilated }\end{array}$ & & Died at 8 months \\
\hline Frank $^{29}$ & 1913 & $\mathbf{F}$ & $4 \frac{1}{2}$ months & 11 months & $\begin{array}{l}\text { Visible en- } \\
\text { largement }\end{array}$ & & & $\begin{array}{l}\text { Much en- } \\
\text { larged }\end{array}$ & $\begin{array}{l}\text { Duod.-jejunos- } \\
\text { tomy : success- } \\
\text { ful. }\end{array}$ \\
\hline Frank $^{29}$ & 1913 & $\mathbf{M}$ & 12 months & 2 years & $\begin{array}{l}\text { Visible en- } \\
\text { largement }\end{array}$ & Enlarged & & & $\begin{array}{l}\text { Operation recom- } \\
\text { mended at } 2 \frac{1}{2} \\
\text { yr., but refused. }\end{array}$ \\
\hline Downes ${ }^{30}$ & 1917 & $\mathrm{M}$ & Birth & $4 \frac{1}{2}$ years & $\begin{array}{l}\text { Visible en- } \\
\text { largement \& } \\
\text { peristalsis }\end{array}$ & & & Enlarged & $\begin{array}{l}\text { Gastro-enteros- } \\
\text { tomy \& division } \\
\text { of pylorus : suc- } \\
\text { cessful. }\end{array}$ \\
\hline Dubose $^{31}$ & 1919 & F & 3.days & 2 months & & Enlarged & & Enlarged & $\begin{array}{l}\text { Gastro-enteros- } \\
\text { tomy \& occlu- } \\
\text { sion of pylorus : } \\
\text { successful. }\end{array}$ \\
\hline Jewesbury $^{32}$ & 1922 & & 3 days & 9 days & & & $\begin{array}{l}\text { Greatly } \\
\text { dilated }\end{array}$ & & Died. \\
\hline $\begin{array}{l}\text { Henske and } \\
\text { Best }^{33}\end{array}$ & 1928 & & Birth & 5 months & & Dilated & Obstructed & & Died at $21 \mathrm{mth}$. \\
\hline
\end{tabular}


The cases in this group are so much more severe in their symptoms and obvious in their physical signs that they bear no great resemblance to the present writer's cases : but their theoretical interest is considerable. They appear to prove beyond doubt that the congenital anatomical abnormality can be a very real factor in the production of arterio-mesenteric compression of the duodenum, and may of itself be sufficient to produce severe symptoms, even death, in early life. It is true that there has been some discussion (Duval ${ }^{37}$ ) whether megaduodenum might not be considered as an essential dilatation comparable to the megacolon of Hirschsprung's disease ; but the evidence in favour of a congenital arterio-mesenteric compression of the duodenum is decisive.

Group 2. Cases of adult type. There are a few cases reported of the occurrence in children of the adult type of chronic duodenal ileus. The details given of these cases are unfortunately very scanty, but the few examples which can be quoted seem to form a group in which the congenital compression of the duodenum is not itself sufficient to give rise to symptoms. Thus the obstructive symptoms arise at a later age than in the first group, and are probably due to the action of accessory factors, as in adults. Only one case is reported with sufficient detail (Quain ${ }^{38}$ ) to be sure of this, but in this instance it seems clear that the onset of gastroptosis determined the onset of the symptoms. In this group the symptoms are of the adult type ; that is to say, painful dyspepsia of obscure origin, flatulence and attacks of vomiting.

The first case of this type was reported by Quervain ${ }^{39}$ in the first edition (1907) of his book on 'Clinical Surgical Diagnosis' (page 273), and it is still contained in the current English edition of the book. Quain's ${ }^{38}$ (1920) case was in a girl of 17 years who started to have symptoms at the age of 8 years. Higgins ${ }^{19}$ (1926) recorded a case in a boy of 7 years who had suffered from epigastric pain and attacks of vomiting 'for some months.' Wilkie ${ }^{22}$ (1927) has stated that the most marked case of duodenal ileus which he has met was in a boy aged 7 years. Hayes and Shaw ${ }^{27}(1929)$ refer without details to such a case (Case 21). Such details of these cases as are available are given in Appendix B.

These two groups contain all the straightforward cases of chronic duodenal ileus in children ætiologically comparable to the ordinary cases in adults. It will be seen that, even allowing a margin for references that cannot be traced, the number of the cases in children is very small. There are, however, certain other cases showing differences from the foregoing which can be collected into two subsidiary groups.

Group 3. Cases with associated conditions. As might be expected to be the case in children, chronic duodenal ileus has been found associated with other conditions and mal-developments. Cases showing excessive mobility of the proximal colon, as in the ordinary colonic type of chronic duodenal ileus of adults are not included here.

Ombrédanne $^{40}(1919)$ has described a case in a girl aged 12 years complicated by volvulus. Wheelon ${ }^{41}$ (1921) has recorded a case which should perhaps be included here. Foucar ${ }^{42}$ (1923) has published two very interesting cases, the first of which falls into this group. A boy of 4 years showed visible gastric peristalsis, and when submitted to X-ray examination during an attack of vomiting, but not during a period of quiescence, showed cluodenal obstruction. At operation adhesive fœtal peritonitis was found resulting in a volvulus of the small intestine, 
which caused secondary and only intermittent closure of the lumen of the duodenum. Waugh ${ }^{43}$ (1928) has reported the case of a boy aged $7 \frac{1}{2}$ years in which there was a tight constriction of the second part of the duodenum caused by a cystico-colic membrane, and also a tendency to arteriomesenteric constriction. Case 2 of the present series is the converse of Waugh's case : here peritoneal thickenings were present but did not seem to be causing obstruction. Judd and White $^{43}$ (1929) have described two cases of duodenal compression in children, one with an abnormally placed mesentery and the other with mal-position of the duodenum. Higgins ${ }^{19}$ (1926), who reported a series of 56 cases of chronic duodenal ileus, including one example in a child as already mentioned, has stated that this condition 'is of rather infrequent occurrence in children unless it is associated with some congenital abnormality.' Synopses of the above cases are given in Appendix B.

Group 4. Cases with disease of the mesentery. Rarely disease of the mesentery can produce compression of the duodenum in a child, as is shown by the following interesting case which clinically resembles the present cases more closely than any others previously recorded.

Foucar $^{42}$ (1923) has reported (Case 2) a case in a boy of 18 months. The child had suffered since birth from attacks of projectile, bilious vomiting, which recurred about once a week, and clearly demonstrated the presence of gastric stasis. Visible gastric peristalsis had been observed by the parents since the 10th month. X-ray examination, made during a quiescent period, revealed no obstruction. At operation the mesentery was found to be very odematous owing to the presence of markedly enlarged glands.

In the presence of visible peristalsis and the absence of radiological evidence of obstruction, this case resembles those of the present series, exhibiting a latent rather than a chronic obstruction; and it is noteworthy that Foucar entitled his paper 'Intermittent duodenal obstruction in children' (see Appendix B.)

Summary.-Having reviewed the literature on duodenal ileus in children it will be well to summarize the present position of the subject. Acute cases of the adult type do not seem to occur in children. Chronic duodenal ileus in children has excited no little theoretical interest chiefly on account of the support which such cases would give to the presence of a congenital ætiological factor in the adult cases; and wonder has been expressed that more is not seen of the condition in children.

Only very few cases have been reported in children. 'In the commonest type the duodenal obstruction is so severe as to produce, usually during infancy, a megaduodenum, forming a visible and palpable tumour; and this group shows clearly that it is possible for the congenital factor alone to be responsible for very severe duodenal compression. Secondly, a very few examples of the adult type of chronic duodenal ileus have been reported in older children. There are also reports of ileus associated with other conditions and maldevelopments, and one case of duodenal compression from disease of the mesentery and its glands.

No cases of true duodenal ileus in children have been found which resemble the present series of cases. The nearest reproduction of their signs and symptoms has been found in a single case of compression of the duodenum by enlarged mesenteric glands (Foucar ${ }^{42}$, Case 2), which the author regarded as due to 'intermittent' obstruction of the duodenum. 


\section{PRESENT SERIES OF CASES.}

The present series consists of nine cases of gastromegaly apparently due to mild duodenal obstruction. They appear sufficiently alike to warrant their inclusion in one clinical group. Two cases were proved at operation to be examples of chronic arterio-mesenteric compression of the duodenum, and the view is taken that the others are due to the same condition.

Characteristics of the series. Before considering the cases in detail it is well to give their characteristics as a group.

1. These cases do not conform to either of the two main types of chronic duodenal ileus which have been already described and reviewed in this paper. They are not so urgently severe as the infantile group with megaduodenum, nor do they show the same symptoms and course as the adult type which has been rarely reported in older children. Rather they seem to conform to the type whose existence has been foreshadowed by Wilkie ${ }^{2: 2}$ in his observation that a proportion of his adult cases gave a history of vomiting attacks in early life, succeeded in adolescence by a quiescent period lasting for many years.

2. The symptoms start in very early life and often from birth. They are for the most part mild. They vary in degree of severity in the different cases, but in no instance are they urgent or spectacular, and they do not readily lead to a suspicion of the presence of organic obstruction. The reason for this is that the congenital obstruction is only severe enough to set up gastric stasis and secondary catarrh (as in the pyloric stenosis of infants), and so loss of appetite is a more troublesome early symptom than is vomiting. The loss of appetite is so severe as to lead to limitation of the amount of food taken, and this limitation keeps the vomiting in abeyance. If this sequence of events is grasped it will be understood how the presence of organic obstruction is at first masked. Later, as the child gets on to solid food and can be pressed to eat against its will, vomiting becomes more troublesome, tending to occur in attacks, accompanied by toxæmia and diarrhœa.

3. Similarly, the physical signs of obstruction are not obtrusive and may require prolonged observation before they are recognized. Chief of them are enlargement of the stomach lying across the upper abdomen, and visible gastric peristalsis. In the shape and position of the stomach, and in the care which has to be expended to elicit visible gastric peristalsis, these cases are rather reminiscent of examples of hypertrophic pyloric stenosis.

4. X-ray examination confirms the presence of obstruction to the evacuation of the stomach, and excludes the stomach itself as the site of the obstruction. It does not show, at all events during periods of freedom from vomiting, the presence of obstruction in the duodenum.

5. The cases as a whole show a tendency towards gradual recovery. This is presumably due in some way to a lessening of the constriction at the duodeno-jejunal flexure by the growth of the child.

6. The obstruction is at first persistent with intermittent exacerbations due usually to gastric distension: but as spontaneous improvement sets in, 
it is probable that only the intermittent obstructive factor is at work, and at this stage suitable dietetic treatment may lead to the cessation of symptoms (see Cases 3 and 7).

Pathogenesis.-In Cases 1 to 7 inclusive it is clear that if the diagnosis of chronic duodenal ileus is correct, compression of the duodenum was present at birth, and that it was the congenital anatomical factor which was responsible for the early symptoms of anorexia, limitation of food, vomiting and malnutrition in so far as these symptoms were present. In Case 8 the history of the first five years of life was unobtainable; and in Case 9 there was so much distension of the colon that it is impossible to assess the importance of any congenital factor in the production of the duodenal compression.

Turning to the influence of the accessory factors, as seen in adults, in producing obstructive symptoms, there seem to be differences to note in these children. In Case 2 the hypertrophy of the gastric wall had 'failed,' and some degree of gastroptosis was present. In Case 9 the abnormality of the colon was sufficient to suggest that this was an example of the colonic type of duodenal ileus as described in adults. In Case 8 the colon was also rather voluminous. But in the other cases it seems impossible to incriminate any of the ordinary accessory factors. Yet distension of the stomach seems undoubtedly to increase the obstruction in these cases, and in the absence of gastroptosis some other explanation is required. When it is remembered how far the distended gastromegalic stomach passes over to the right, the pyloric portion of the stomach coming to lie right over the pylorus, it may be suggested that this displacement adds to the obstruction at the root of the mesentery.

Frequency.-Two of the nine cases were seen some years ago (Case 9 in 1923, and Case 7 in 1926). In Case 9 the presence of obstruction to the evacuation of the stomach was not recognized until 1929 ; and Case 7 which showed marked visible gastric peristalsis when first seen, was not understood. Case 1 came under the writer's care in December, 1928, and the exact diagnosis was determined at operation in May, 1929. In the twelve months from December, 1928, therefore, seven cases were seen. During the same period three other cases were met. One was the man referred to in the section on prognosis, apparently a recovered case. The second, a most marked case of gastromegaly, was a boy seen in a convalescent home by the courtesy of Dr. Hugh Raven, and not included in the series owing to lack of clinical details available. The third was a boy seen at hospital in whom the evidence of obstruction was insufficient for publication.*

It is, of course, a commonplace that cases of special interest are always met in droves, yet the experience of the past year is suggestive. In four out of the nine cases visible gastric peristalsis was proceeding at the time of their first examination, though it had not been previously noted: in the other five cases a good deal of time and trouble was spent on proving the existence of obstruction. It is therefore possible that were evidence of obstruction looked for in older children with the care that is expended on the same point in young babies, cases of gastromegaly due to chronic duodenal ileus of the rather latent type described here would be found of no great rarity.

* Another case (female) was shown by me at the Children's Section of the Royal Society of Medicine on Feb. 28th, 1930.-R.M. 
Sex incidence,-Of the nine cases of the series only two were in girls. The three additional examples mentioned above were all males. No great stress can be laid on the sex incidence worked out on only (at the most) twelve cases. But the point needs mention here because the sex incidence of chronic duodenal ileus in adults shows a preponderance of females over males. This is attributed to the greater frequency of visceroptosis in the female sex. In the present series in children the factor of visceroptosis is of little importance, the congenital factor being of chief moment. If, then, the sex incidence as mentioned above is more than accidental, it may be that it reflects the greater frequency of congenitai anatomical abnormalities in the male sex.

\section{Synopsis of present cases.}

It is convenient to give here only the salient clinical features of the nine cases included in the present series. The full case-records are given in Appendix A.

Case 1. B.R., male, born February, 1926. At birth he weighed $5 \frac{1}{4} \mathrm{lb}$. and was frail and atonic. During the first year his appetite was so bad that feeding was very difficult. During the second year vomiting began and became worse after the 18th month. It occurred in attacks usually following attempted increases in the diet. Preceded by hiccup, extra coating of the tongue and refusal of food, vomiting usually started at night. The vomit was forcible, copious, containing food and bile-stained mucus. Diarrhøea with much mucus in the stools immediately followed the vomiting. Progress during the second year was very slow. He was first seen by the writer in July, 1928, aged 2 years and 4 months. He was very thin $\left(18 \frac{1}{2} \mathrm{lb}\right.$.) but not toxic in appearance; nor was he stunted in growth except by the presence of scoliosis. Gastric peristalsis was observed at this date for the first time. An X-ray examination showed enlargement of the stomach but no gastric stasis.*

The boy came under the care of the present writer in December, 1928. On a dry diet it was possible to avoid the attacks of vomiting, but not to give enough food to lead to progress. An increase in the amount of food given would in one or two days lead to hiccup, increased gastritis, increased refusal of food, visible gastric peristalsis : obvious preludes to an attack of vomiting. In February, 1929, a second X-ray examination was made (H.C.G.). This showed a large stomach with good peristalsis but considerable stasis. The duodenal cap appeared normal and the distal parts of the duodenum were not seen (Fig. 1). The abdomen was opened in May, 1929, and there was found chronic duodenal ileus with enlargement and hypertrophy of the stomach and duodenum, and atrophy of the jejunum. A posterior gastro-jejunostomy was performed. After operation, although the symptoms of obstruction were relieved, the stomach decreased in size, and the chronic gastritis cured, only slow progress was made. In February, 1930, a third X-ray examination (H.C.G.) showed that the stomach retained an 8 oz. meal for two or three hours, and was empty in 3 hours. This result was so satisfactory that the comparative lack of progress since the operation appeared due in part to the difficult psychology of the child and in part to defective tissue assimilation.

Case 2. A.E., male ; first seen October 3rd., 1929, aged 5 years. Was brought up for vomiting and wasting. At birth he weighed $8 \frac{3}{4} \mathrm{lb}$. From birth he took feeds slowly and without appetite. At 7th week began projectile vomiting and was suspected of pyloric stenosis, but was ultimately diagnosed as 'indigestion.' Vomiting continued off and on, and at 18 months on solid food it increased. It recurred every 3 or 4 weeks in attacks accompanied by fever, drowsiness, rapid loss of weight with mucus in the stools. Hiccup was a frequent symptom. He continued on these lines, eating extraordinarily little, so that at 5 his condition was worse than at 3 years.

At 5 years he weighed $34 \mathrm{lb} .14 \mathrm{oz}$. He was quite an invalid child and his appetite was extremely bad, amounting to refusal of food. On the very meagre diet he could be prevailed upon to take, there was no vomiting. The abdomen showed enlarged stomach, gastric splashing

* The X-ray examinations for which Dr. Gage is responsible are initialled (H.C.G.). Every photograph has been reduced on the same scale, so that all are strictly comparable to each other. 
and feeble visible peristalsis. The wall of the stomach felt thickened. The stools were fatty. X-ray examination (H.C.G.) showed a large atonic stomach, very poor peristalsis and severe gastric delay (Fig. 2).

A diagnosis was made of duodenal obstruction with failure of the compensatory gastric hypertrophy. At operation (November 11th., 1929) chronic duodenal ileus was found.

The stomach was found enlarged, flaccid, but showing hypertrophy. The duodenum was enlarged and hypertrophied so that it appeared the size of an adult duodenum. This change was apparent as far as the duodenum could be traced (first and second parts), and the jejunum was normal. No disease of the mesentery or its glands was found, but a small amount of unexplained clear fluid was present in the abdominal cavity. A posterior no-loop gastrojejunostomy was performed.

In the ensuing three months very slight progress was made, both the lack of tone of the stomach and the psychological condition of the child proving severe handicaps to progress.

Case 3. M.M., girl, aged $5 \frac{1}{2}$ years. Birth weight $4 \mathrm{lb}$. From birth there were great difficulties in feeding and fairly frequent vomiting of projectile type. With the vomiting occurred diarrhœa with mucus and sometimes blood in the stools. The baby was habitually cross. Hiccup was common. Feeding seemed to give rise to discomfort. Refusal of food continued throughout the $2 \mathrm{nd}$, 3rd and 4 th years, and progress was very slow. The vomiting settled down into attacks typical of gastric stasis : the diarrhœa continued to be associated with the vomiting. An X-ray examination at the age of 5 years and 5 months showed a large stomach covering over the pyloric region. Emptying time was only 2 hours.

First seen at $5 \frac{1}{2}$ years (December, 1928). Weight $36 \frac{1}{2} \mathrm{lb}$. Since the X-ray examination she had been put on a dry diet and no vomiting had occurred. The stomach was large, its walls felt hypertrophied, and splashing was elicited. No gastric peristalsis was seen at that time. The dry diet was continued.

In Mareh, 1929, she was seen again. She had continued free of all vomiting and nausea and had gained weight. An X-ray examination (H.C.G.) showed the stomach was average in size, its peristalsis suggested hypertrophy, but there was no stasis. The duodenal cap appeared normal (Fig. 3).

In September, 1929, definite visible gastric peristalsis was seen after inflation of the stomach. There had been no return of the vomiting.

Diagnosis. Although proof of obstruction to the emptying of the stomach was in this case difficult to obtain, the appearance of visible gastric peristalsis ultimately confirmed what the history of the case and the thickening of the gastric wall had at first suggested. In view of the similarity to Case 1 a diagnosis was made of chronic duodenal ileus in which symptoms were passing off.

Progress was satisfactory on the régime of a dry diet with gastric antisepties. No vomiting occurred for 16 months, and the appetite improved.

Case 4. H.D., male, aged 4 years. Brought (November 28, 1929) for malnutrition and diarrhœa. Always frail and had made slow progress. For the past year no progress had been made. Was subject to attacks of diarrhœa, with large, pale and offensive motions. Hiccup was frequent. On very restricted diet owing to the diarrhœic attacks, he eat well and was not sick. At 4 years he looked very frail; weight, $28 \mathrm{lb}$. His tongue was coated, and breath foul. The upier abdomen was large and the outline of the enlarged stomach was clearly seen. Its wall felt thickened and gastric peristalsis was observed. X-ray examination (H.C.G.) showed an enlarged stomach tending to hide the outlet. Peristalsis was powerful and suggested hyperperistalsis. There was a small residue at $3 \frac{1}{2}$ hours. The duodenal cap was normal (Fig. 4).

I iagnosis : duodenal obstruction, probably due to chronic duodenal ileus.

Progress on pounded food with drinks in between meals was satisfactory and resulted in gain of weight.

Case 5. 1).M., male, aged 2 years and 4 months. Brought (May 29, 1929) for enlarged abdomen, which had been present since the age of 9 months. There were no symptoms of ill-health. His weight was $25 \mathrm{lb}$. The upper abdomen was very protuberant. The stomach outline was clearly seen, vigorous gastric peristalsis was visible, and the wall of the stomach felt definitely thickened. Splashing was easily elicited, The tongue was slightly coated. 
The bowels normal. The X-ray examination (H.C.G.) showed that the stomach was much enlarged. Peristalsis was vigorous and indicative of hypertrophy. More than $50 \%$ of the meal remained in the stomach at $3 \frac{1}{2}$ hours. The duodenal cap appeared normal. The colon was distended and perhaps large (Fig. 5).

Diagnosis: duodenal obstruction probably due to ileus.

As there were no symptoms and good progress was being made, no treatment was ordered.

Case 6. A.A., male, aged 6 years. Brought (November 15, 1929), for asthma. Appetite had always been rather poor, and became worse with change on to solid food at 18 months. Recently appetite had been very poor and there were periods of refusal of food. For past 2 years his weight had gone down. There had been only occasional vomiting, but when it occurred it was projectile in type. There was much flatulence and persistent hiccup after meals. Much gurgling in the stomach had been heard. The upper abdomen was protuberant. The outline of the stomach was clearly visible. Well marked peristalsis was seen. The wall of the stomach felt thickened. X-ray examination (H.C.G.) showed the stomach apparently only a little larger than normal. Hyper-peristalsis was present at first but died down later. There was a large residue at $4 \frac{3}{4}$ hours. No view of the duodenal cap was obtained (Fig. 6).

Diagnosis : mild obstruction probably due to chronic duodenal ileus.

Pounded and minced foods were ordered to be taken as dry as possible. Drinks only in between meals. The foot of the bed was raised at night. With these measures the stomach became less obvious and the peristalsis much less in evidence.

Case 7. (First case seen.) E.McC., male, aged 8 years. Brought up in January, 1926, for poor digestion. Had always been a very poor feeder. No pain and seldom sick. Hiccup was very persistent. Abdomen was said to have been enlarged from 18 months to 6 years. Recently he had shown improvement. Bowels rather constipated : attacks of diarrhœa occurring about every two months. At 8 he was 49 in. in height, pale and thin. The upper abdomen was enlarged, the outline of the stomach clearly visible, its walls felt thickened, and well marked peristalsis was seen. X-ray examination showed a very large stomach hiding the duodenal cap and emptying slowly (Fig. 7).

It was recognized in 1926 that there was obstruction to the outlet of the stomach which did not show in the skiagrams. It was thought that this might be due to kinking in an enlarged atonic stomach. It is now suggested that the case was one of chronic duodenal ileus. On dry meals improvement occurred. At 11 he weighed $66 \frac{1}{2} \mathrm{lb}$, and was at school eating ordinary diet. His appendix had been removed without any post-operative complications.

Case 8. J.G., male, aged 12 years. Brought (July 31st, 1929), for mal-shaped abdomen. Early history not obtainable. Abdomen was enlarged by age of 5 years. Has progressed slowly and is subject to attacks of vomiting occurring about four times a year. Vomitus contains bile. Is at boarding-school, and is showing general improvement especially since he started drilling exercises. Tonsils were removed at 10 without incident. The upper abdomen was very large where the stomach could be seen much distended. Splashing was obtained but no peristalsis could be seen even after inflation of the stomach. X-ray examination (H.C.G.) showed enlargement of the stomach with normal peristalsis and emptying time. Iuodenal cap was normal. No ileal stasis was observed, but the colon was voluminous and the transverse portion dipped low in the pelvis in the erect position. There was considerable colonic stasis (Fig. 8).

The diagnosis of duodenal obstruction is not clear, yet the emptying of such a large stomach in normal time suggests gastric hypertrophy. It is suggested that this is a case of chronic duodenal ileus in which the voluminous colon acts as an accessory factor in producing the symptoms of obstruction. No such symptoms were present when the boy was under observation.

Case 9. D.N., girl, first seen at the age of 2 years and 4 months (September 1925), for enlarged abdomen. The abdominal enlargement had been present for at least a year. There were no gastric symptoms except flatulence. She eat hungrily of the restricted diet permitted. She was not thin and had a good colour. She was subject to alternate attacks of diarrhœa and constipation. X-ray examination showed great dilatation of the stomach and colon (Fig 9). The stool contained a mild excess of fat. She was kept on a fat-free diet which seemed to keep her free of flatulence. In March, 1928, a second X-ray examination showed much the same condition as before. In May, 1929, in distending the stomach with a draught of soda water 
well-marked gastric peristalsis was obseived. It is suggested that this is a case of chronic duodenal ileus in which the ' $\mathrm{drag}$ ' of the colon is the chief factor in producing obstruction of the duodenum. In $2 \frac{3}{4}$ years she had gained $16_{4}^{1} \mathrm{lb}$. and grown $7 \frac{1}{2}$ inches. Treatment on the same lines is being continued.

\section{Symptomatology.}

It is noticeable that the severity of the symptoms varies very much in the nine cases recorded here. In Cases 1, 2, 3, and 4 the degree of invalidity was considerable, and the children had been under medical supervision most of their lives. On the other hand, in Case 5 , although the signs of obstruction were very definite, there was almost complete freedom from symptoms except for enlargement of the abdomen. In the other cases the degree of illness occasioned by the condition lay between these two extremes.

The mechanical factors at work in the production of symptoms have already been discussed, and presumably the variation in the severity of the symptoms depends chiefly on the variation in the degree of obstruction with which the child is born, and whether spontaneous improvement has set in. In addition to these mechanical factors, there are two other factors which may have a minor influence on the production of the symptoms, namely, the capacity of the gastric wall to undergo compensatory hypertrophy, and the chronic gastritis which may accompany the gastric stasis. The first must depend on the condition of the child at birth, its capacity to progress, and its freedom from debilitating illnesses, and so on.

Date of onset of symptoms. - As might be expected it is impossible to give any precise date at which symptoms become recognizable as indicating organic obstruction. In the worst instances difficulties arose from the earliest days. In Cases 1 and 3, from birth there was great difficulty in getting the child to take its feeds, although neither was regarded as an ill infant at first. Cases 2 and 7 had been taken as infants to specialists on account of indigestion and failure to progress. Case 4 at nine months was regarded as a delicate child but was thought to be free of anything that would ultimately prove harmful.

Where symptoms could be traced back to the earliest days it was found that they appeared worse in the second than in the first year of life, and in several instances they definitely increased in severity when the child began to take more solid food at about the age of eighteen months. In more than one case the mother has stated that whatever might be wrong with the child's stomach, it was certainly present from birth; and this statement may be taken to prove that there is no particular time at which there is a development of symptoms in the sense that a previously healthy child becomes an ill child.

The ages of the nine cases when they were first seen by the writer are not without interest for the reason that in no instance had the presence of any obstructive factor in the case been previously recognized. These figures, together with the dates of the onset of symptoms are given in Table 2 .

Earliest symptoms. - Emphasis has already been laid on the fact that the earliest symptom may be loss of appetite rather than vomiting. The limitation of the amount of food which the child can be made to take keeps the vomiting in abeyance at first. Malnutrition and lack of progress are present in mostcases. 
Diarrhœa, especially associated with the attacks of vomiting, may be an early symptom. Taken as a whole the early symptoms have two points of interest about them : their nature depends largely on the amount of food which the child is given, and is more suggestive of indigestion than of obstruction.

Symptoms.--The symptoms may now be considered individually.

Anorexia. In the severer cases, as has already been emphasized, it is anorexia rather than vomiting which is the most troublesome symptom. In some instances there is complete lack of appetite, even for breakfast or the beginning of a meal, and this develops into real refusal of food. If food is pressed on the child there is vomiting. Should the increase in the diet be made very gradually, the vomiting may be postponed for a day or two, but careful observation will show that, however the character of the food be modified, there is a definite limit to the amount of it which can be tolerated. The refusal of food may be quite as severe as in the untreated case of coliac disease, and the atmosphere of the nursery at meal-time may be much the same. The gastromegaly child may show all the freaks of misbehaviour over

TABLE 2.

EARLy histories in present series.

\begin{tabular}{|c|c|c|c|}
\hline $\begin{array}{l}\text { Case } \\
\text { No. }\end{array}$ & $\begin{array}{l}\text { Age of earliest } \\
\text { symptoms. }\end{array}$ & $\begin{array}{c}\text { Age when } \\
\text { first seen } \\
\text { (years). }\end{array}$ & Earliest symptoms. \\
\hline 1 & From birth & $22^{4} \frac{4}{2}$ & Anorexia, malnutrition, vomiting. \\
\hline 2 & From birth & 5 & Anorexia, vomiting, malnutrition. \\
\hline 3 & From birth & $5 \frac{1}{2}$ & Anorexia, vomiting, malnutrition. \\
\hline 4 & Before 11 months & 4 & Malnutrition, diarrhoea. \\
\hline 5 & Nine months & $2{ }_{1}^{4}: \bar{z}$ & Enlarged abdomen. \\
\hline 6 & ? from birth & 6 & Anorexia. \\
\hline 7 & ? from birth & 8 & Anorexia. \\
\hline 8 & $?$ & 12 & Misshapen arodomen, vomiting. \\
\hline 9 & Sixteen months & $22_{1}^{4}$ & Enlarged abdomen. \\
\hline
\end{tabular}

food that are seen in cœliac disease and are so apt to lead to a diagnosis of nervous anorexia. In the milder cases the anorexia, although very persistent, is less spectacular. The absence of appetite is not due to the occurrence of pain after food, for of this there is very little : doubtless it is to be explained as the result of the gastric stasis which is present in all cases, and the gastritis which may be associated with it in the worst cases.

Vomiting. In the early stages the vomiting occurs sporadically after food, is projectile in type and copious in amount. Later it tends to occur in attacks and so, like any other recurrent vomiting in children, can be described as 'cyclical.' This alteration is due in part, no doubt, to the increase in the size of the stomach and improved capacity for storing food in it, but to a large extent it seems the result of the régime adopted. Where the child is fed down to its diminished appetite, vomiting can be avoided : where attempts are made to press the food, vomiting will occur. 


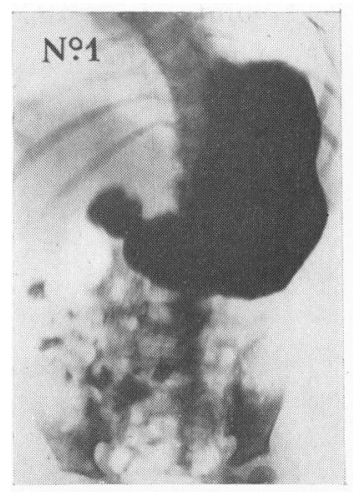

10 minutes, prone.

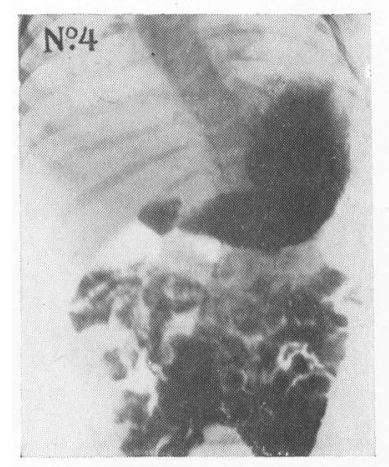

2 hours, erect.

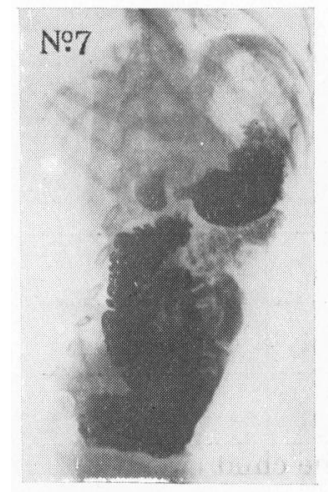

$3 \frac{1}{2}$ hours, lateral.

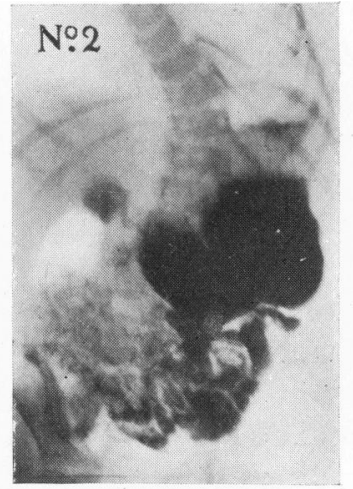

20 minutes, erect.

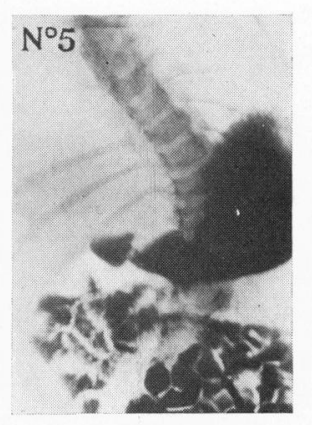

2 hours, prone.

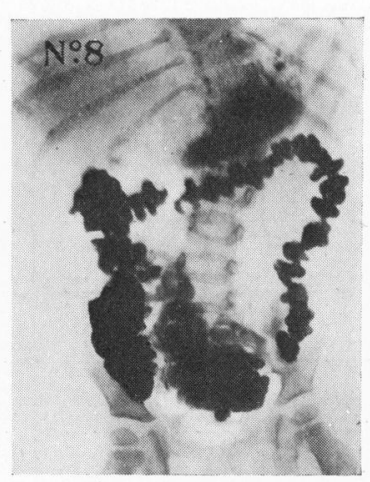

7 hours, pone.

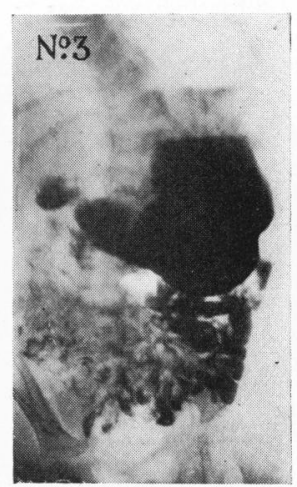

20 minutes, erect.

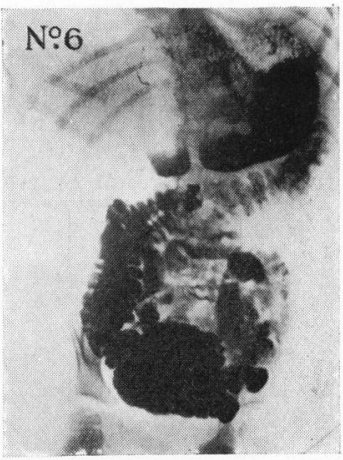

$3 \frac{1}{2}$ hours, prone.

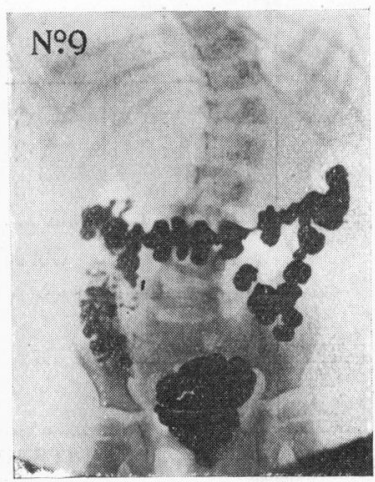

24 hours, erect.

Fifi, 1. Case 1 : opaque meal, 
The vomit is large in amount, forcible in character, and contains food and usually mucus. Bile may be recognizable in it, but this is by no means invariable; its colour, as Frank ${ }^{22}$ has noted, may be lost by dilution. Careful observation of the vomiting in relation to the nature and time of previous meals, will establish the presence of gastric delay.

An attack of vomiting may come on suddenly or be preceded by a day or two of premonitory symptoms, such as increase in the coating of the tongue and in the refusal of food. Persistent hiccup may also give warning of an attack. Immediately before the sickness starts there may be abdominal pain. With the onset of the vomiting, there is fever, drowsiness, dehydration and rapid loss of weight. Almost at once diarrhoa ozcurs, and the stools contain mucus which, from its sodden appearance, may be taken to come from the stomach. The vomiting, owing to the unavoidable starvation, soon subsides, and the child is quickly rid of its toxic symptoms. The lost weight, however, is only regained slowly.

During the attack of vomiting, therefore, thcre is evidence of considerable toxæmia, from which at other times these cases are for the most part frce. Duodenal stasis is known to produce severe toxicosis; but in the attacks described here, although there is no question of the poisoning of the child, there seems nothing sufficiently peculiar to distinguish them as of duodenal origin.

TABLE 3.

Fat analyses of feces in present series. (Dr. H. Perkins.)

\begin{tabular}{|c|c|c|c|c|c|c|c|}
\hline \multirow{3}{*}{$\begin{array}{l}\text { Case } \\
\text { No. }\end{array}$} & \multirow[t]{3}{*}{ Date. } & \multicolumn{4}{|c|}{ Fat in dried frees. } & \multirow[t]{3}{*}{ Diet. } & \multirow[t]{3}{*}{ Remarks. } \\
\hline & & \multirow{2}{*}{$\begin{array}{c}\text { Total } \\
\text { per cent. }\end{array}$} & \multicolumn{3}{|c|}{ Per cent. of fxeal fat. } & & \\
\hline & & & Soaps. & $\begin{array}{l}\text { Free } \\
\text { fatty } \\
\text { acids. }\end{array}$ & $\begin{array}{c}\text { Neutral } \\
\text { fat. }\end{array}$ & & \\
\hline \multirow[t]{6}{*}{1} & $10: 7: 28$ & $10 \cdot 4$ & $69 \cdot 2$ & $27 \cdot 0$ & $3 \cdot 8$ & Low fat & Undigested starch. \\
\hline & $6: 12: 28$ & $24 \cdot 0$ & $92 \cdot 6$ & $5 \cdot 0$ & $2 \cdot 4$ & Half fat & \\
\hline & $31: 12: 28$ & $16 \cdot 8$ & $62 \cdot 0$ & $21+4$ & $16 \cdot 6$ & Half fat & \\
\hline & $6: 3: 29$ & No & apparent & excess & & Full fat & Undigested starch. \\
\hline & $6: 6: 29$ & No & apparent & excess & & Full fat & After operation. \\
\hline & $14: 99: 29$ & No & apparent & excess & & Full fat & After operation. \\
\hline \multirow[t]{3}{*}{2} & $22: 10: 29$ & $59 \cdot 2$ & $48 \cdot 0$ & $41 \cdot 2$ & $10 \cdot 8$ & Full fat & \\
\hline & $3: 11: 29$ & $13 \cdot 2$ & $51 \cdot 5$ & $30 \cdot 3$ & $18 \cdot 2$ & Low fat & \\
\hline & $19: 2: 30$ & $16 \cdot 0$ & $57 \cdot 5$ & $40 \cdot 9)$ & $2 \cdot 5$ & Low fat & After operation. \\
\hline 4 & $1: 12: 29$ & $23 \cdot 8$ & $58 \cdot 2$ & $34 \cdot 3$ & $7 \cdot 5$ & Full fat & Indicanuria. \\
\hline 6 & $22: 11: 29$ & $22 \cdot 0$ & $60 \cdot 0$ & $29 \cdot 1$ & $10 \cdot 9$ & Full fat & Undigested starch. \\
\hline 7 & $7: 1: 26$ & $23 \cdot 0$ & $52 \cdot 9$ & $37 \cdot 3$ & $9 \cdot 8$ & Full fat & \\
\hline \multirow[t]{4}{*}{9} & $4: 9: 25$ & $46 \cdot 2$ & $34 \cdot 9$ & $30 \cdot 6$ & $34 \cdot 5$ & Full fat & Inticanuria. \\
\hline & $22: 2: 26$ & $37 \cdot 2$ & $29 \cdot 2$ & $55 \cdot 6$ & $15 \cdot 2$ & Half fat & \\
\hline & $23: 6: 26$ & $23 \cdot 2$ & $65 \cdot 5$ & $24 \cdot 2$ & $10 \cdot 3$ & Low fat & \\
\hline & $5: 12: 27$ & $19 \cdot 2$ & $58 \cdot 3$ & 37.5 & $4 \cdot 2$ & Low fat & \\
\hline
\end{tabular}


In the only case in which careful watch was kept for the occurrence of acetonuria (Case 1), none was found before the vomiting declared itself.

The question of the mechanism by which vomiting is produced has been discussed in the section on pathogenesis.

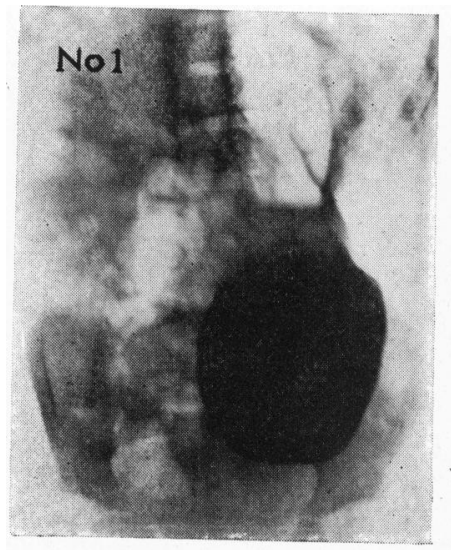

5 miriutes, erect.

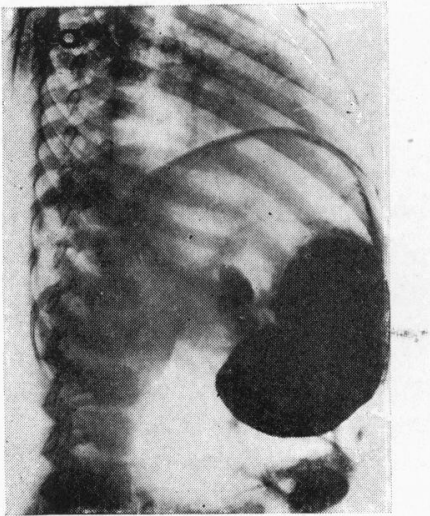

2 hours, lateral.

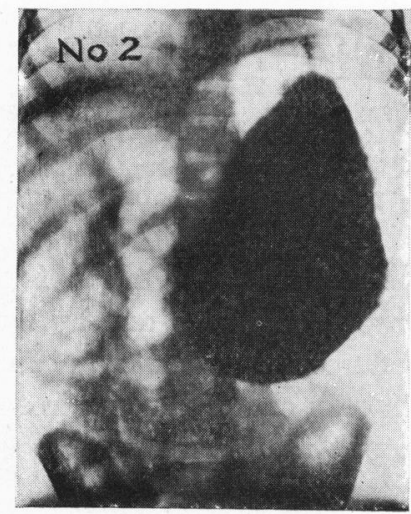

10 minutes, erect.

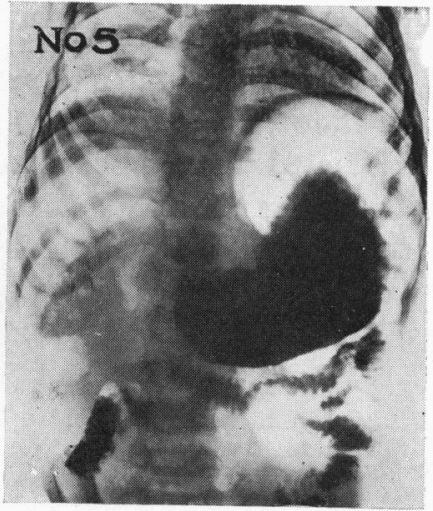

$: 3 \frac{1}{2}$ hours, prone.

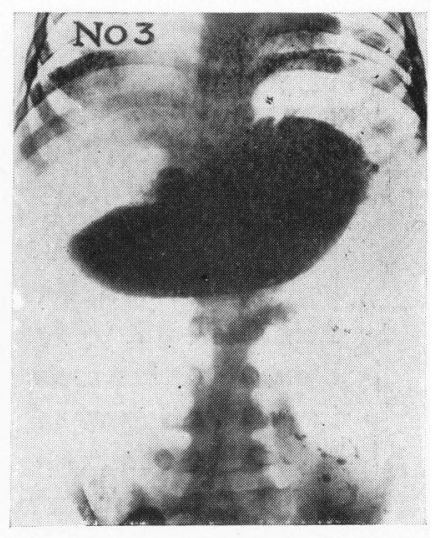

2 hours, prone.

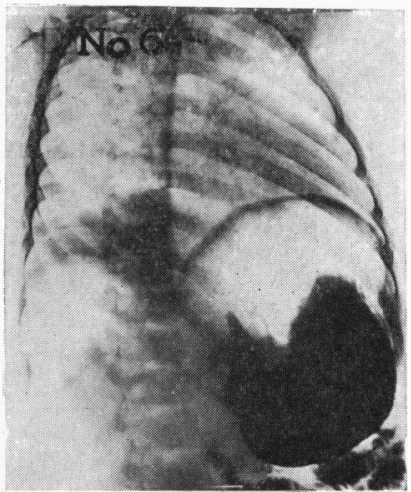

$3 \frac{1}{2}$ hours, oblique.

Fig. 2 Case 2 : opaqte meal.

GASTRITIS. Chronic gastritis is a rare disease in young children, but it is present in most of these cases of chronic duodenal obstruction. This is interesting in view of the fact that hypertrophic pyloric stenosis is the chief, if not the only, cause of really chronic gastritis in young babies. Doubtless in both conditions it is secondary to the gastric stasis. The signs of it are the persistently coated tongue, foul breath, mucus in the stools and vomitus. 
Bowels. Where there is derangement of the bowels it is chiefly in the direction of constipation, due to the underfeeding from which these children as a whole suffer. During the vomiting attacks diarrhœa may supervene. This has alrcady been sufficiently described in the preceding paragraph.

Two other abnormalities require mention. First, where the case is severe enough to be complicated by chronic gastritis, the motions may at any time contain mucus. The thickened, sodden appearance of this shows that it comes chiefly from the stomach. In Case 1, following the relief of the obstruction by gastro-jejunostomy, the signs of gastritis in time clearcd up, after which the motions no longer contained mucus.

Secondly, fatty stools may at timcs be passed. This was the case in Cases 1 and 2, and again in Case 9 coliac disease was suspected before tho presence of obstruction was recognized. On low-fat diets the percentages of fæcal fat sank to figures lower than those usually obtained in cases of cœliac disease. Other cases showed normal percentages of fat in the stools. Failure in fat-splitting was found in only one of the specimens analysed (Table 3).

These observations suggest that there may be from time to time failure in fat-absorption owing to interference with the flow of bile out of the duodenum; and this impression receives some confirmation from the fact that in Cases 1 and 2, after gastro-jejunostomy, íatty stools were still occasionally passed. Unfortunately none of these particular specimens were submitted to chemical analysis.

It must be borne in mind that an excess of unabsorbed fat in the intestine may set up very considerable distension of the colon. The writcr has reported ${ }^{45}$ a case of cœliac disease in which megacolon was completely cured by a régime of fat-deprivation, in spite of the fact that for a long time the colon had been immensoly dilated and had exhibited visible peristalsis. It is therefore possible that in cases of duodenal obstruction the voluminous appearance of the colon may be due to nothing more than defective fat-absorption.

Pain. Pain in all the cases reported here was practically absent except immediately before actual vomiting. In this particular these cases differ from the reported examples of chronic duodenal ileus in adults and obstruction by band in children. For the most part they seem free even of discomfort, though doubtless both discomfort and pain could be brought about were food prassed on the child. Case 1 , for instance, a most delicate koy, existing on a minimum of food, was a happy active little fellow, quite content to do snything execpt take food. In Case 2 thrre were complaints of discomfort in the abdomen, but hore it appeared that the compensatory hypertrophy of the gastric wall had failed, and atony and some degree of gastroptosis had supervened. Whore the tone of the stomach kecps good, and the child's limited capacity for food is respected, very little pain or diseomfort scems t) occur.

It is not altogether easy to understand why there is so little pain in these cases, although it must be admitted that in infants such a disorder as hypertrophic pyloric stenosis rarely gives rise to pain. Presumably it is because the persistent compression of the duodenum is so slight in degree. When the 
distension of the stomach comes into play, the occlusion of the duodenum is increased, and pain and vomiting occur. Another possible explanation of the absence of pain is that the patency of the pylorus prevents a rise in the duodenal pressure.

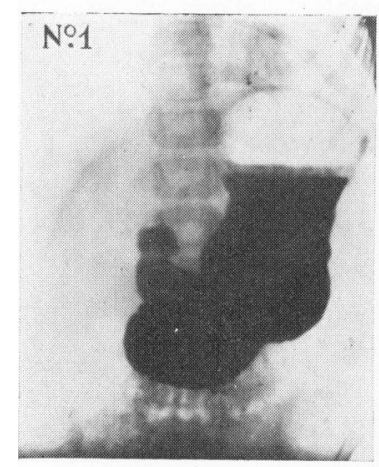

5 minutes, erect.

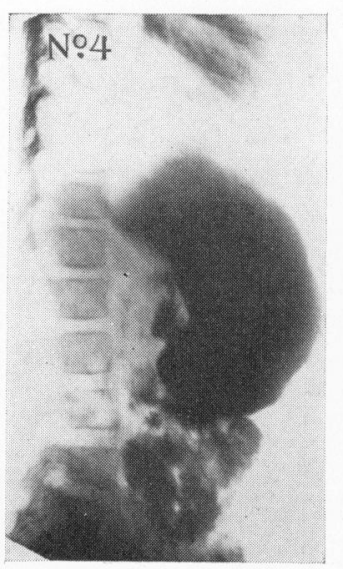

25 minutes, lateral.

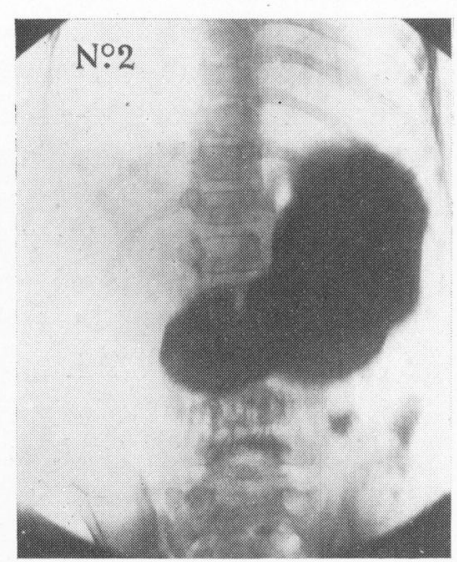

10 minutes, prone.

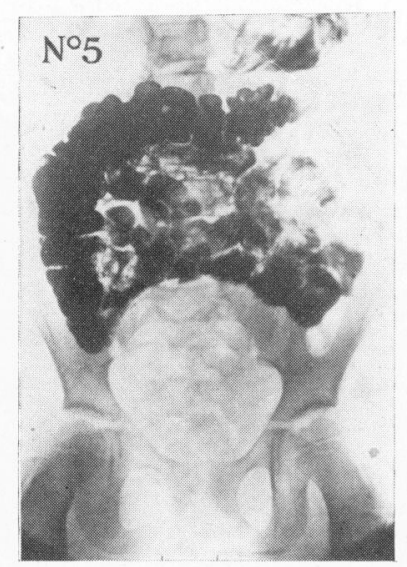

3 hours, prone.

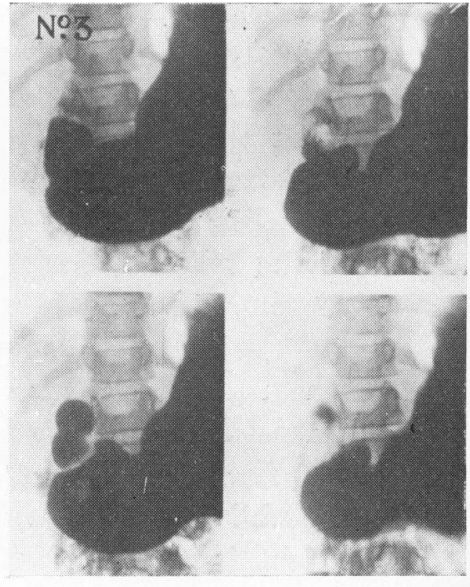

20 minutes, prone; serial of cap.

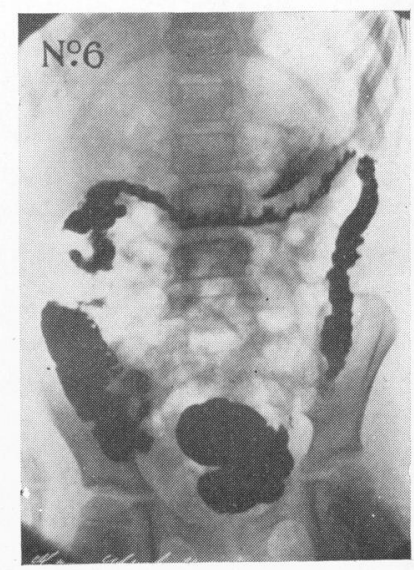

7 hours, prone.

Fig. 3. Case 3 : opaque meal.

HICCUP AND BORBorygmus. Hiccup is a very common symptom in all these cases although statements on its occurrence will seldom be volunteered. In most cases it occurs after meals, and in some it will recur after almost every meal. In those whose food capacity is very small, and who are therefore always living on the verge of vomiting, persistent hiccup may be a prelude to an attack of sickness. In practice hiccup forms a useful guide to the amount 
of strain that is being put on the stomach by the particular diet in use. Doubtless the symptom depends on the distension of the stomach. In several cases excessive borborygmi were noticed to occur an hour or so after food.

NutRITION AND GROWTH. The factor governing the under-development of these children is one of almost pure food-deprivation (underfeeding) and is accompanied by very little in the way of chronic toxæmia. In this they differ from the usual case of chronic indigestion in children, which is of intestinal origin and shows considerable chronic constitutional poisoning. In the present series only one child (Case 7) had the appearance of toxæmia, and he was suspected of having an unhealthy appendix. Most of the children, though thin, had clear skins, and several had quite pink complexions and showed nothing of the sallow unhealthy look of the 'intestinal child.' During the attacks of vomiting thəre is, as has been already mentioned, considerable toxæmia, but this soon passes off as the vomiting ceases. The only other sign of toxæmia which may be present is that of indicanuria, which may occur at any time when the bowels are loose.

For these reasons, although in severe cases (such as Cases 1, 2, 3, and 4) the children have the appearance of smallness and frailty, their growth in height is not interfered with to the same extent as their growth in weight. They are not stunted to the same degree as is, for instance, the untreated case of cœliac disease. There the stunting of the growth is due to the combined effects of fat-deprivation and chronic toxæmia : in these duodenal cases it is due only to food-deprivation, and is more analogous to the condition found in œsophageal obstruction by Sheldon and Ogilvie ${ }^{46}$.

It is worth mentioning that in the severer cases where there has been opportunity for close observation (Cases 1 and 2), alterations in weight of half a pound or more occur very easily in these children. It has been disappointing to note how little real improvement accompanies a gain of weight of a pound or two, though doubtless it is comforting to bear this in mind when the increase disappears in a day of upset and vomiting. It seems as though the best criterion of improvement in such difficult cases is their mental development, a gradual expansion in their interest in outside matters and an increased capacity for doing things for themselves.

Psychological CONDition. In tha severer cases where symptoms are present from the carliest months it is hardly possible for the psychological development of the child to proceed quite normally. A child who has never known what it is to want to take food, who perhaps has had all his life to have special food and to take all meals alone, can hardly fail to be influenced by such factors, so that the study of the psychology of these little underfed children is full of interest, particularly if the attempt is made to compare it with that of the child with coeliac disease. In some ways, especially over their tricks to get out of eating, they are rather alike, and yet there are differences. In the duodenal case there is, roughly speaking, pure under-development, while in the cœliac child there is an added element of psychological perversion; and it is tempting to suppose that the difference is due to the fact that in the one there is pure food-deprivation while in the other there is an added chronic toxæmia. 


\section{Physical signs.}

The physical signs of this type of chronic duodenal compression are those of obstruction, and they cannot be distinguished from those of pyloric stenosis clinically except possibly by the recognition of bile in the vomit and theabsence

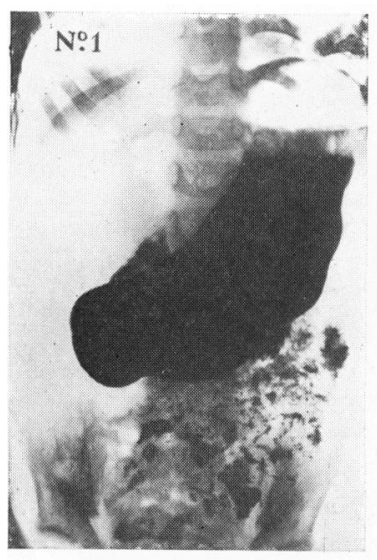

5 minutes, erect.

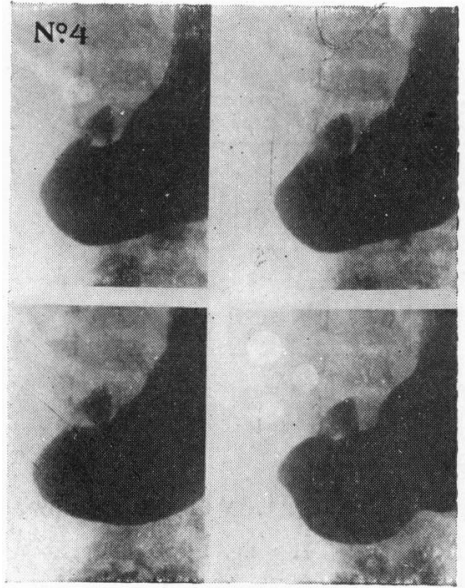

20 minutes, prone ; serial of cap.

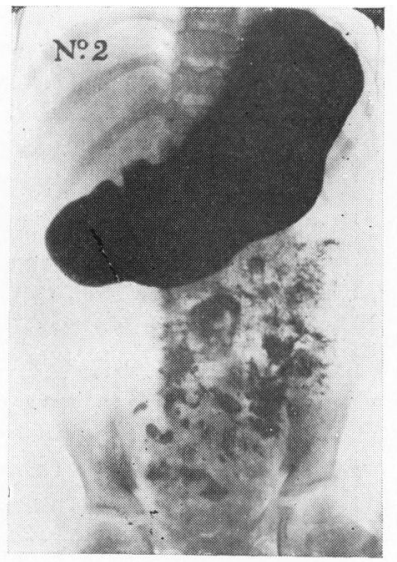

10 minutes, prone.

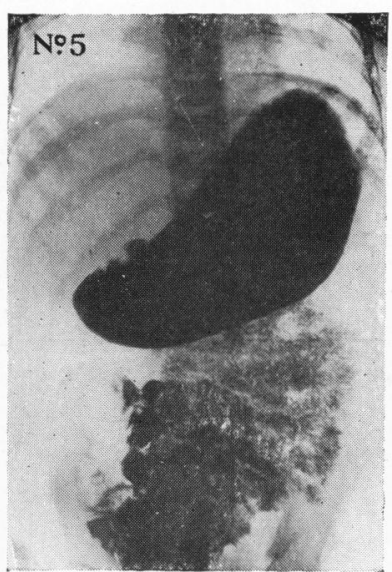

1 hour, prone.

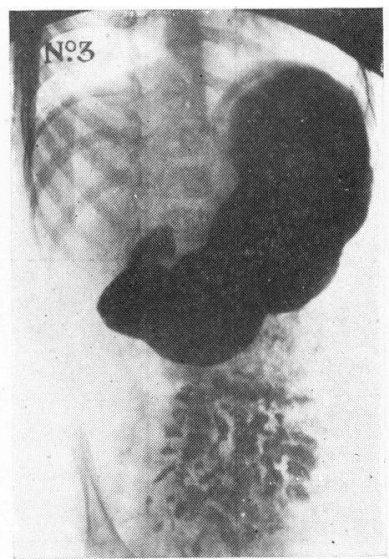

15 minutes, prone.

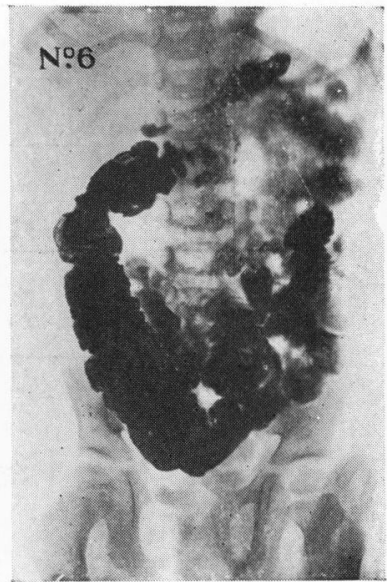

3 hours, prone.

Fic. 4. Casle 4: opaque neal.

of a pyloric tumour. In none of the cases included in the presint series was the duodenum obviously enlarged as in the group of infantile cases of megaduodenum mentioned earlier in this paper.

On inspection the cnlargement of the abdomen is peculiar in that the protuberance affects the upper quadrants only. In more than one of the series it was the enlargement of the abdomen which was the cause of the child's coming under observation. 
TABLE 4.

Clinical evidence of obstruction in present series.

\begin{tabular}{|c|c|c|c|c|}
\hline \multirow{3}{*}{$\begin{array}{c}\text { Case } \\
\text { No. } \\
1\end{array}$} & \multirow{3}{*}{$\begin{array}{l}\text { Sex. } \\
-\mathrm{M}\end{array}$} & \multicolumn{2}{|c|}{ Clinical evidence of obstruction. } & \multirow[t]{2}{*}{ Remarks. } \\
\hline & & Symptoms. & Physical signs. & \\
\hline & & $\begin{array}{l}\text { Anorexia, vomiting, } \\
\text { hiccup, gastritis. }\end{array}$ & $\begin{array}{l}\text { Enlarged stomach, vomiting } \\
\text { projectile, visible peristalsis, } \\
\text { palpable stomach, splashing. }\end{array}$ & Operation. \\
\hline 2 & M & $\begin{array}{l}\text { Anorexia, vomiting, } \\
\text { hiccup, gastritis. }\end{array}$ & $\begin{array}{c}\text { Enlarged stomach, vomiting } \\
\text { projectile, visible peristalsis, } \\
\text { palpable stomach, splashing. }\end{array}$ & Operation. \\
\hline 3 & $\mathbf{F}$ & $\begin{array}{l}\text { Anorexia, vomiting, } \\
\text { hiccup, gastritis. }\end{array}$ & $\begin{array}{l}\text { Enlarged stomach, vomiting } \\
\text { projectile, visible peristalsis, } \\
\text { palpable stomach, splashing. }\end{array}$ & $\begin{array}{l}\text { Improving when first } \\
\text { seen. }\end{array}$ \\
\hline 4 & M & $\begin{array}{l}\text { Anorexia, gastritis, } \\
\text { (diarrhœa). }\end{array}$ & $\begin{array}{l}\text { Enlarged stomach, visible peri- } \\
\text { stalsis, palpable stomach, } \\
\text { splashing. }\end{array}$ & $\begin{array}{l}\text { Improved with medical } \\
\text { treatment. }\end{array}$ \\
\hline 5 & $\mathbf{M}$ & (Enlarged abdomen!. & $\begin{array}{l}\text { Enlarged stomach, visible peri- } \\
\text { stalsis, palpable stomach, } \\
\text { splashing. }\end{array}$ & $\begin{array}{l}\text { No symptoms, progress } \\
\text { good. }\end{array}$ \\
\hline 6 & $\mathbf{M}$ & $\begin{array}{l}\text { Anorexia, occ. vomg., } \\
\text { hiccup, flatulence } \\
\text { (asthma). }\end{array}$ & $\begin{array}{l}\text { Enlarged stomach, vomiting } \\
\text { projectile, visible peristalsis, } \\
\text { palpable stomach, splashing. }\end{array}$ & $\begin{array}{l}\text { Progressed slowly with } \\
\text { medical treatment. }\end{array}$ \\
\hline 7 & $\mathbf{M}$ & $\begin{array}{l}\text { Anorexia, occ. vomg., } \\
\text { hiccup. }\end{array}$ & $\begin{array}{l}\text { Enlarged stomach, visible peri } \\
\text { stalsis, splashing. }\end{array}$ & $\begin{array}{l}\text { Improving when first } \\
\text { seen : progress good. }\end{array}$ \\
\hline 8 & $\mathbf{M}$ & $\begin{array}{l}\text { Vomiting (enlarged } \\
\text { abdomen). }\end{array}$ & Enlarged stomach, splashing. & $\begin{array}{l}\text { Improving when first } \\
\text { seen : progress good. }\end{array}$ \\
\hline 9 & $\mathbf{F}$ & $\begin{array}{l}\text { Flatulence (enlarged } \\
\text { abdomen). }\end{array}$ & $\begin{array}{l}\text { Enlarged stomach, visible peri- } \\
\text { stalsis (megacolon). }\end{array}$ & $\begin{array}{l}\text { Progressed well with } \\
\text { medical treatment. }\end{array}$ \\
\hline
\end{tabular}

It is essential that the abdomen should be cxamined when the child is lying on its back. Then, frequently, the outline of the stomach can be seen quite distinctly and its size, shape and position show that the organ is in a state of tonicity quite unlike the dropped flabby stomach of atony. The greater curvature crosses the middle line an inch or more above the level of the umbilicus ; and often the body of the stomach extends well over to the right, covering the pyloric region as in hypertrophic pyloric stenosis. X-ray examination confirms this in many cases.

The size of the stomach can be determined not only by inspection, but also by the combined method of auscultation and light direct percussion. Splashing, which can be elicited at almost any time, proves that the dilated viscus is stomach and not colon. Hypertrophy of the wall of the stomach can be detected by palpation with assurance in a marked case in a thin child : in others it may be suspected. 
Visible gastric peristalsis is, of course, the accepted sign of obstruction to the outflow of the gastric contents and hypertrophy of the musculature of the gastric wall. In these cases the peristaltic wave comes out from under cover of the left ribs and passes across to the right just as in the pyloric stenosis of infants. The three waves, all visible at once and so significant of hypertrophy of the stomach wall, are often well seen. Visible gastrie peristalsis

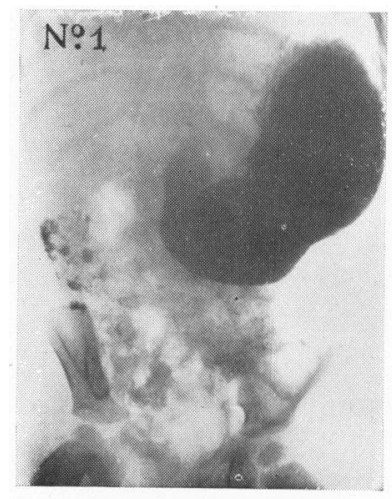

5 minutes, prone.

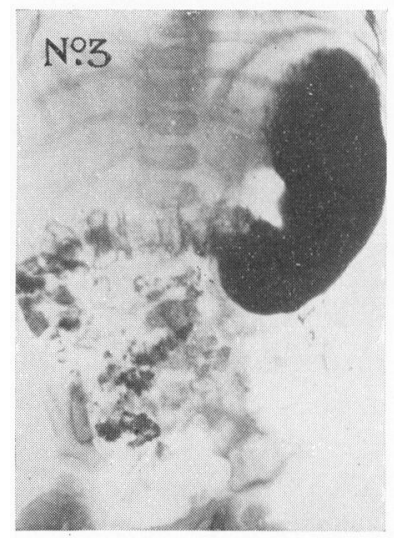

1 hour, prone.

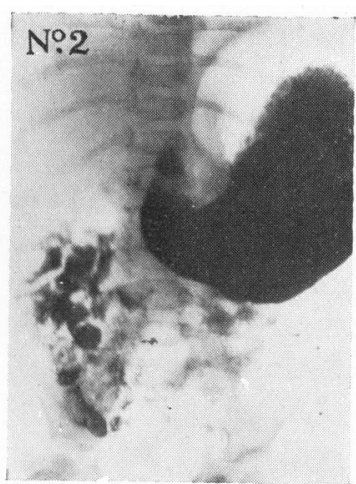

30 minutes, prone.

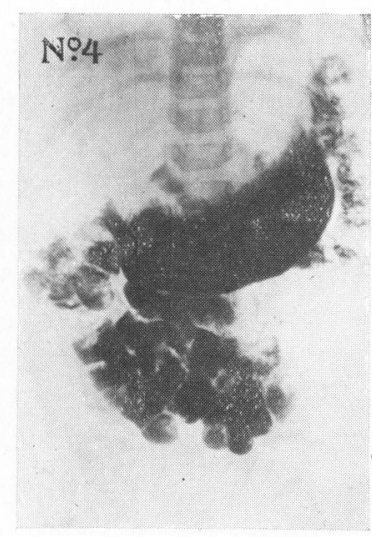

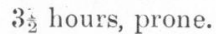

Fit: 5 Case j: Opacile hear.

has been seen in all the cases of this series except one (Case 8). In four (Cases $1,5,6$ and 7 ) it was observed in routine examination of the child on the first occasion that it was overhauled. In Cases 2 and 4 it was observed after the children had been fed, but without inflation of the stomach. In Cases 3 and 9 it was observed only after the stomach had been inflated with a draught of soda water, but in both instances the peristalsis then was very well marked. It must be mentioned that both these children were seen only occasionally 
and in consulting-room practice, so that it was not possible to test them after meals. Doubtless peristalsis would have been visible under such circumstances. In order to test the reliability of the inflation test in children it has been carried out in several thin children as controls, but the appearance of the stomachs in these cases has been quite different and no visible peristalsis has been seen.

Radiographic examination. In the present series of cases the value of the radiographic examinations has been confined to two points in diagrosis. First, it confirms the presence of obstruction high in the alimentary tract by demonstrating the enlargement of the stomach, suggesting hypertrophy of the gastric musculature, and proving the presence of gastric stasis. Secondly, it usually demonstrates satisfactorily that the site of the obstruction is not in the stomach or at the pylorus. Such assistance in diagnosis is of great value, but further than this X-ray examinations have not helped in this series: in no instance has there been obtained such direct evidence of duodenal obstruction as stasis, enlargement or cogwheel indentation affecting the duodenum.

That the distal parts of the duodenum do not show in the X-ray examinations of any of the present cases cannot be taken to negative the diagnosis of duodenal compression of the type dealt with here. The two cases (Cases 1 and 2) which showed dilatation and hypertrophy of the duodenum at operation, failed like all the others to display the distal parts of the duodenum under the X-rays. In another suspected case (not included in this series) an attempt was made to obtain a shadow of the whole of the duodenum by introducing barium cream through a duodenal tube. This manœuvre led to the satisfactory display of the duodenal cap, but the rest of the duodenum remaincd unseen.

The type of duodenal compression in these cases, as has been explained in the section on pathogenesis, is pictured as a mild chronic (persistent) compression, with intermittent periods of increased obstruction due to the action of the accessory obstructive factors, particularly distension of the stomach or colon. It may be that if the radiographic examination were to be made when the obstruction is accentuated, as during a bout of vomiting, the duodenum would show as distended throughout its course. Foucar found this to be so in one of his cases where the duodenum was compressed by a volvulus (see Appendix B). During a quiescent stage the duodenum appeared normal under the X-rays, but during an attack of vomiting it could be seen as enlarged throughout its length. No opportunity of examining any of the present cases radiographically during a bout of vomiting has occurred.

It must also be remembered that the condition of the duodenum as found at operation in Cases 1 and 2 was one of comparative enlargement or $y$. It was large for a small child, but in neither case was it larger than th $:$ of a normal adult. This probably explains why the distal parts of it do not show in the radiological examination of these cases.

To get even such results as have been obtained here there are certain fallacies to be avoided and precautions to be taken.

(1) If the meal given is too small or too fluid, the size of the stomach may be masked and the occurrence of gastric stasis missed. The same results may 


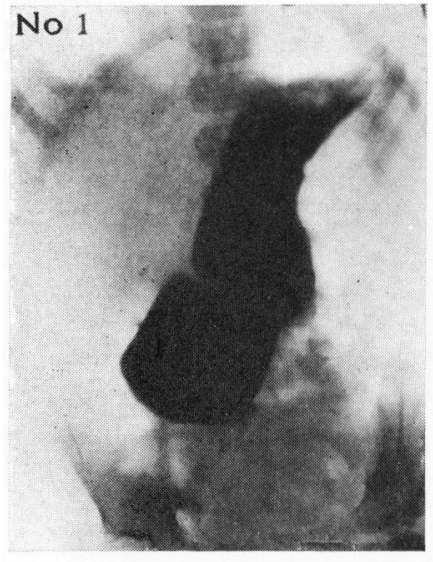

5 minutes, erect.

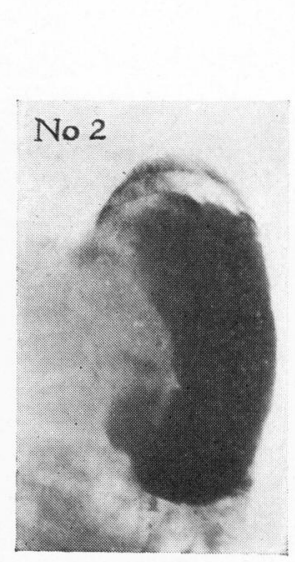

5 minutes, lateral.

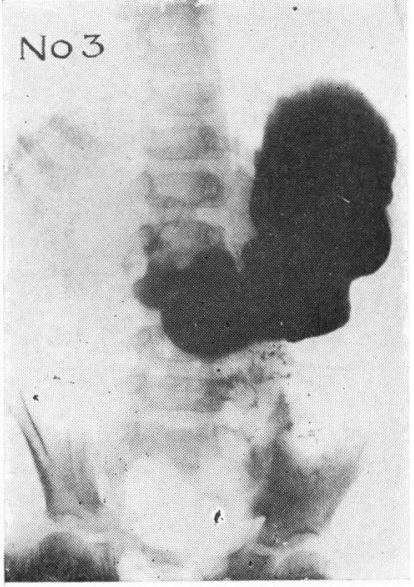

10 minutes, prone.

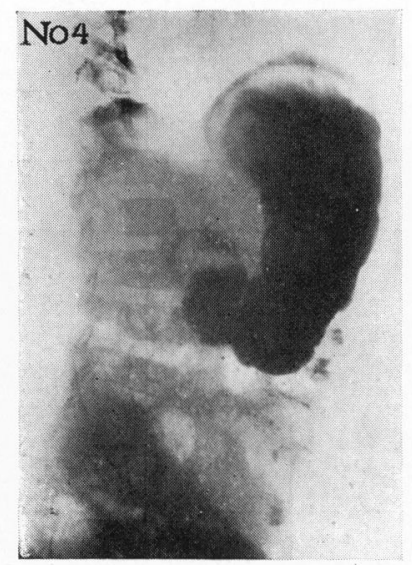

15 minutes, oblique.

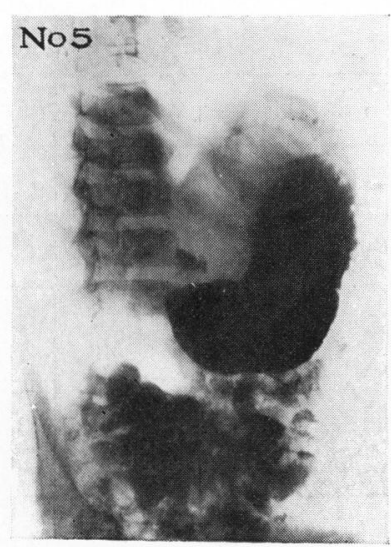

$1 \frac{1}{3}$ bours, oblique.

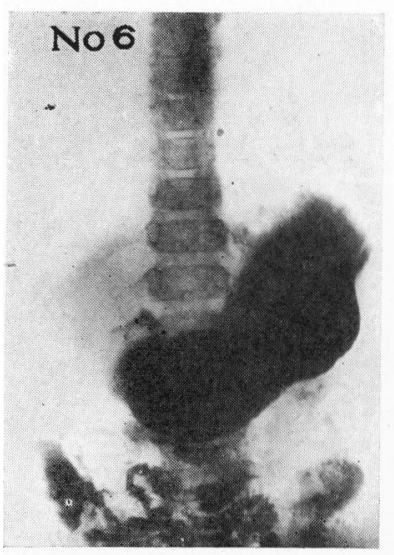

$1 \frac{1}{2}$ hours, prone.

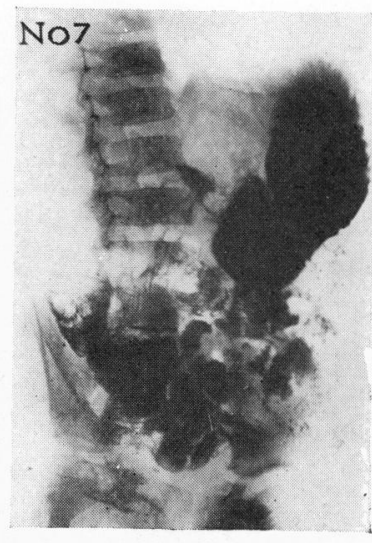

$4 \frac{3}{4}$ hours, oblique.

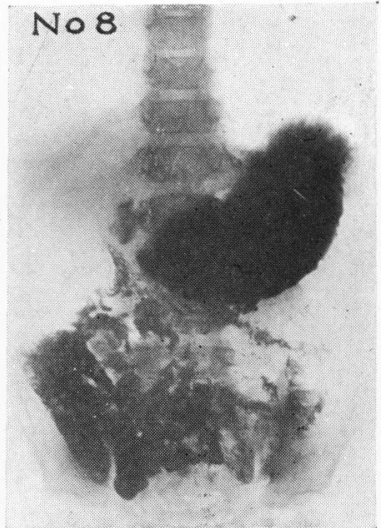

$4 \frac{3}{4}$ hours, prone.

Fig. 6. Case 6 : opaque meal. 
come from the use of a meal which does not contain food for digestion, as for example, a watery suspension of barium in tragacanth. Contrariwise, too large a meal may give rise to a false impression of gastromegaly, though such a fallacy is usually apparent to the experienced radiologist.

(2) The use of a standard barium meal is desirable, and such a meal was used in the examination of Cases 1 (second and third examinations), 2, 3 (second examination), 4, 5, 6 and 8 . A somewhat arbitrary. variation in the amount of the meal administered was made according to the age of the patient. The meal should be given after a sufficiently long period of fasting to ensure an empty stomach.

TABLE 5.

Radiographic EVIDENCE OF OBSTRUCTION IN PRESENT SERIES.

\begin{tabular}{|c|c|c|c|c|c|c|}
\hline \multirow{2}{*}{$\begin{array}{l}\text { Case } \\
\text { No. }\end{array}$} & \multirow{2}{*}{$\begin{array}{l}\text { Erilargemerit } \\
\text { of stomach. }\end{array}$} & \multirow{2}{*}{$\begin{array}{c}\text { Hyper- } \\
\text { peristalsis. }\end{array}$} & \multirow{2}{*}{$\begin{array}{l}\text { Emptyirg } \\
\text { time. }\end{array}$} & \multicolumn{2}{|c|}{ Duodenum: } & \multirow[t]{2}{*}{ Remarks. } \\
\hline & & & & Cap. & $\begin{array}{l}\text { 2nd and } \\
\text { 3rd parts. }\end{array}$ & \\
\hline 1 & Enlarged & Present & Increased & Normal & INot scen & \\
\hline 2 & Much enlarged & Not seen & Much increased & Normal & Not seen & \\
\hline 3 & Doubtful & Suspected & Not increased & Normal & Not seen & \\
\hline 4 & Enlarged & Present & Increased & Normal & Not seen & \\
\hline$\tilde{5}$ & Much enlarged & Present & Increased & Normal & Not seen & \\
\hline i & Erlarged & Present & Increased & Irreģular & Not seen & $\begin{array}{l}\text { ? Cap imperfectly } \\
\text { filled. }\end{array}$ \\
\hline$\tau$ & Much enlarged & - & Increased & Irregulor & Not scen & $\begin{array}{l}\text { ? Cap imperfectly } \\
\text { filled. }\end{array}$ \\
\hline 8 & Enlerged & - & Increased & Normal & Not seen & Colon voluminous \\
\hline 9 & Much enlarged & Present & Increased & Not scen & Not seen & Megacolon. \\
\hline
\end{tabular}

(3) In many instances the enlargement of the stomach is so great as to hide the duodenal cap in an antero-posterior view. This difficulty may be overcome by employing an oblique or semi-oblique exposure. In other cases a preliminary course of dieting may reduce the size of the stomach sufficiently to expose the duodenal cap in the antero-posterior view.

(4) The size of the duodenal cap is so variable within physiological limits that it is not safe to diagnose obstruction at the lower end of the duodenum unless the enlargement of the cap is greater than that seen in any of the present cases. In many instances the size of the cap appeared to be in normal proportion to the size of the stomach, and since the stomach was enlarged it might be argued that the cap was also enlarged. But in other instances the duodenal cap at the time of the examination appeared not at all enlarged, and so no definite evidence of duodenal obstruction has been accepted in these cases from a consideration of the size of the duodenal cap. 


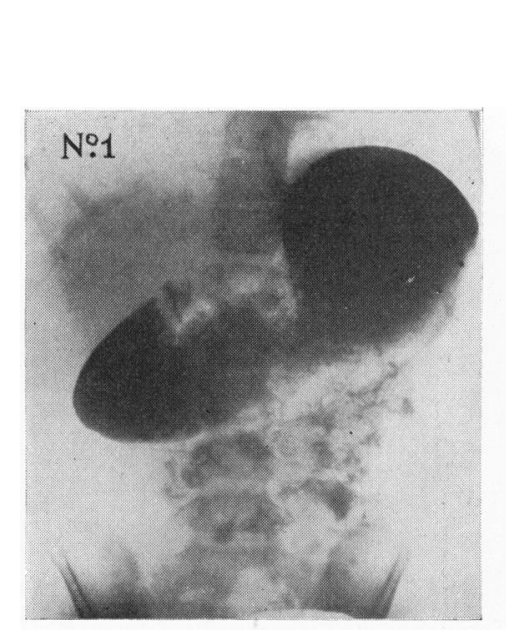

5 minutes, prone.
CHRONIC DUODENAL ILEUS

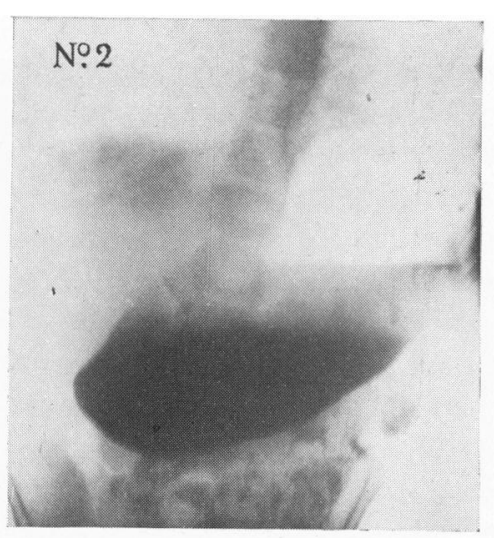

10 minutes, erect.

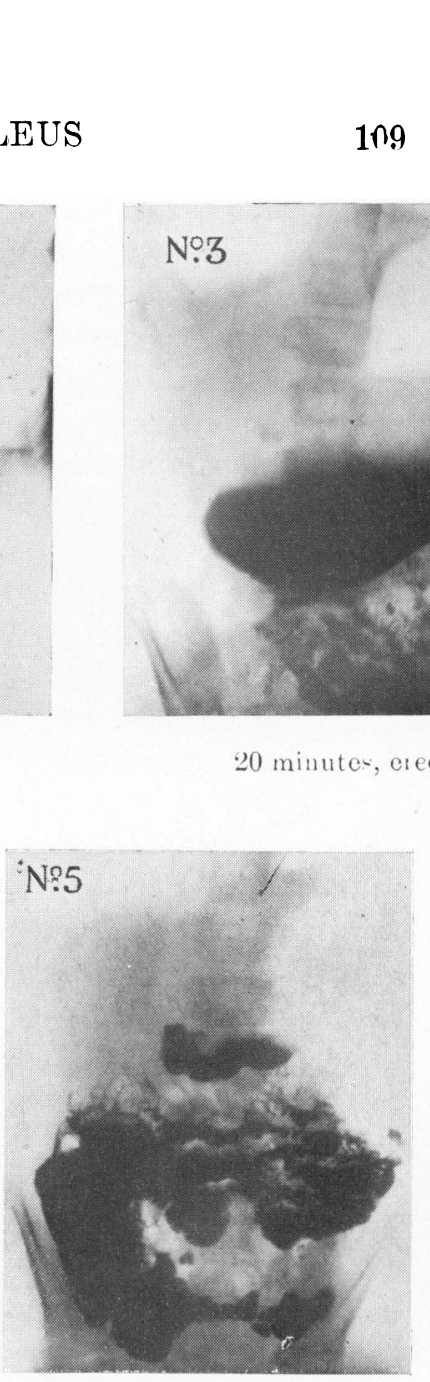

$3 \frac{1}{2}$ hours, prone.

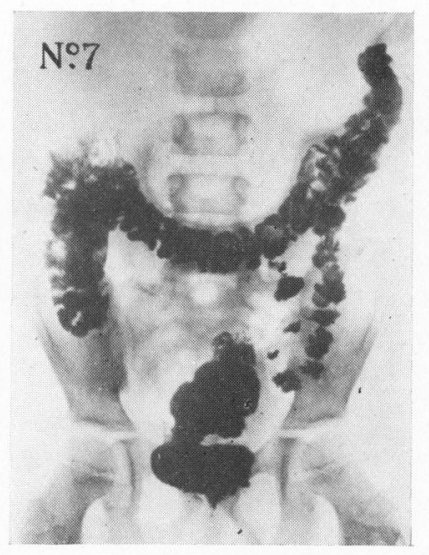

48 hours, prone.

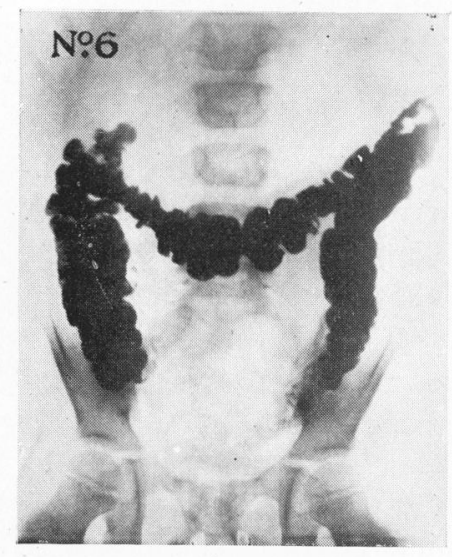

24 hours, prone. 


\section{Diagnosis.}

The diagnosis of chronic duodenal obstruction in these cases is reached in two stages : first, by the clinical and radiographic evidence of obstruction at a high level in the alimentary tract; and secondly, by the absence of radiographic evidence of obstruction in the stomach or at the pylorus. These points have received sufficient attention in the foregoing pages.

The causas of chronic duodenal obstruction in children may be divided into intrinsic and extrinsic groups.

Intrinsic. 1. Congenital duOdenal atresia or stenosis. This group has been the subject of papers by Cowell ${ }^{47}$ (1911), Cautley ${ }^{48}$ (1919), Cameron ${ }^{49}$ (1925), and Sheldon ${ }^{50}$ (1926), in the English literature. The type of obstruction may be (a) by membrane, perforated or imperforate; (b) by fibrous cord, pervious or impervious; and (c) by blind ending of the duodenum. Life in such cases is only rarely prolonged for more than two or three weeks. Exceptions to this rule have been reported by authors whose cases have lived (without operative relief) for some months: Smellie ${ }^{51}, 3$ months; Keith ${ }^{52}, 9$ months ; v. Koos ${ }^{53}, 13$ months; Buchanan ${ }^{54}, 18$ months; Cautley ${ }^{48}, 18$ months. It must also be mentioned that a few cases of duodenal stenosis, taken to be of congenital origin, have been found in adults (Silcock ${ }^{55}$, Moore ${ }^{56}$, Perry and Shaw ${ }^{57}$, Curling ${ }^{58}$, Terry and Kilgore ${ }^{59}$ ). It is, however, evident that, although congenital stenosis may give rise to megaduodenum, as in the cases reported by Jewesbury ${ }^{32}$, and Variot and Cailliau ${ }^{35}$, and thus simulate the severe type of duodenal ilcus in infants (see Group 1, p. 86), there is no great resemblance between these cases of stenosis and the type of chronic duodenal ileus described in the present series of cases.

2. Cicatrization of peptic ulcer of the newborn. The writer has met one instance of this cause of gastromegaly (see p. 133). It is, however, of great rarity and presents no difficulty in diagnosis with modern methods.

Extrinsic. In any case of chronic duodenal obstruction in a child more than a few weeks old, the cause of the obstruction is more likely to be extrinsic than intrinsic.

1. Obstruction by perttonfal band. See below.

2. Arterio-mesenteric obstruction. See below.

3. Obstruction by volvulus. Mention has already been made of the cases reported by Ombrédanne ${ }^{40}$ and Foucar ${ }^{42}$. In the first, volvulus complicated duodenal ileus; and in the second a volvulus compressed the duodenum. Many other cases in which the volvulus, although due to developmental causes, is not directly concerned with the duodenum, have been recorded. Important papers on the subject are by Rixford ${ }^{60}$ (1920), Dott ${ }^{61}$ (1923), and Poynton ${ }^{62}$ (1924). In these cases the attacks of obstructive vomiting are accompanied by great pain, and so differ from the condition described here.

4. Obstruction by diseased mesentery. This type of case as described by Foucar ${ }^{42}$ (see Appendix B) simulates in the comparative latency of its obstructive symptoms the type of duodenal ileus described in this paper. In the present series, however, there has been no real difficulty in excluding active disease of the abdominal organs. 

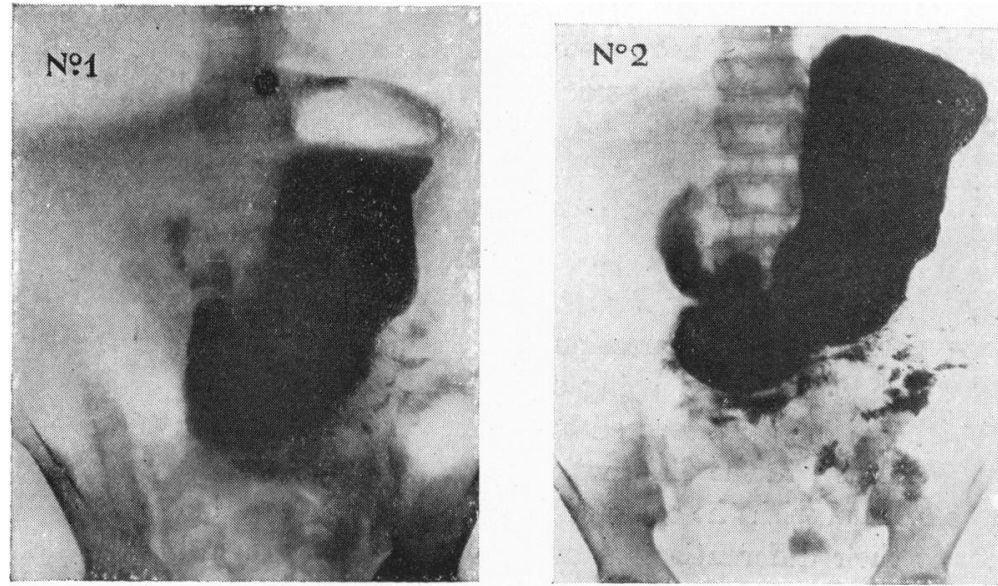

5 minutes, erect.

10 minutes, prone.

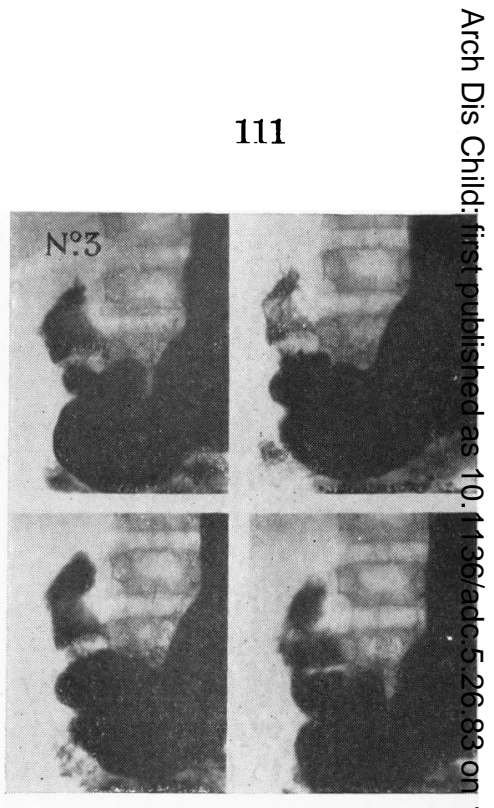

15 minutes, prone; serial of cap. $\frac{D}{2}$

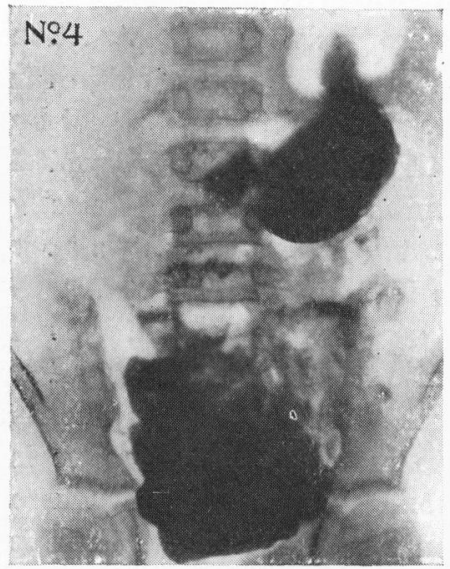

2 hours, prone.

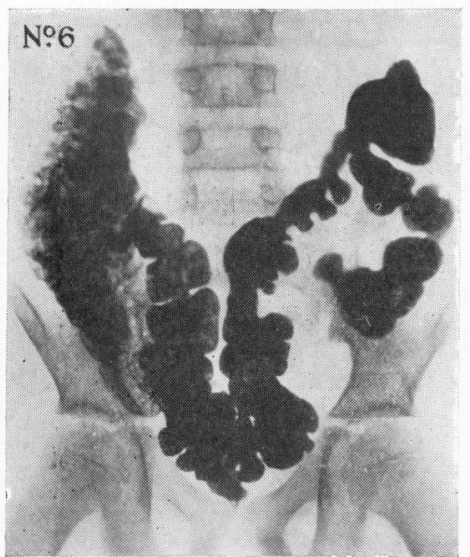

24 hours, erect.

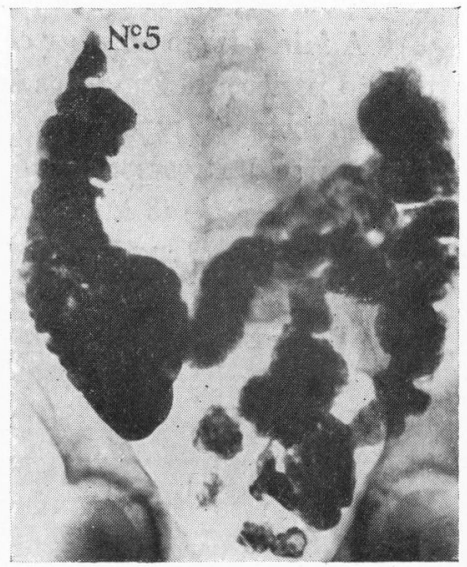

? hours, prone.

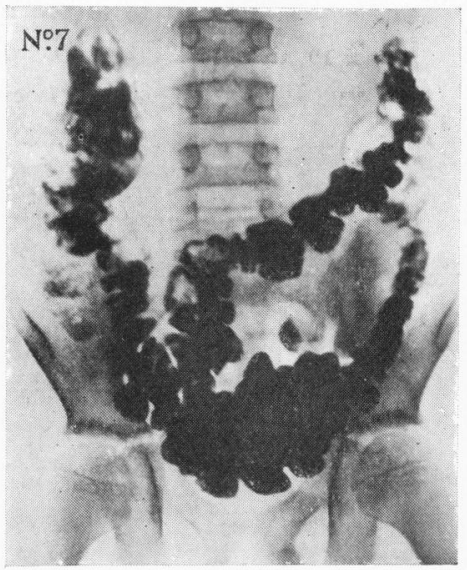

48 hours, prone. 
5. OBStRUCtion by MALFORMation OF THE MESENTERy OR Kinking of THE DUODEnum. Cases of this type have been recorded by Waugh ${ }^{43}$, cind Judd and White ${ }^{44}$ (see Appendix B). Denzer ${ }^{63}$ has described congenital duodenal obstruction from mal-rotation of the intestine. Adult cases have been reported by Duval and Gatellier ${ }^{64}$.

6. Obstruction by tumour. Hohlbaum's ${ }^{36}$ case of compression of the duodenum by tumour in a new-born infant has been mentioned. Instances of this typa have been resorded in adults by Bird ${ }^{65}$.

7. Obstruction By pancreas. Compression of the duodenum by the pancreas has been described, the bowel boing enclosed in a ring of pancreatic substance. The subject has been discussed by Anderson ${ }^{66}$.

Undoubtedly the chief difficulty in the differential diagnosis of the present type of duodenal ileus is concerned with the cases of duodenal obstruction due to peritoneal bands. Nor is their differentiation unimportant. In the band cases operation is advisable and usually curative, whereas in the present type of duodenal ileus it would seem that operation is only a last resort and disappointing in its results unless a duodeno-jejunostomy is possible.

A fairly large number of cases in children of chronic duodenal obstruction due to peritoneal band has been described, and the literature on the subject is too extensive to reproduce here. Mention may be made of a recent paper by Higgins and Paterson ${ }^{34}$ (1926). In most cases the bands are of congenital origin, and little is known of acquired periduodenitis in children. Clinically the cases of obstruction by band seem to fall into two groups. First, a very severe type giving rise to obstructive symptoms in early life, sometimes to megaduodenum, and so comparable to the first group of cases of duodenal ileus described above. Secondly, a type giving rise to dyspeptic symptoms, usually painful and interrupied by attacks of vomiting, in which the presence of an obstructive factor may be far less easy to recognize. This group is comparable to the second or adult type of chronic duodenal ileus. There appear, however, no cases reported of obstruction by band in which there is quite the same latent type of obstruction, causing very little pain and gradually improving spontaneously, as in the group of cases with which we are here concerned. But this is not to say that it is impossible for them to exist.

The differentiation of the cases described here and cases of duodenal obstruction by band cannot be said at the present time to be altogether clear ; and although the writer has not taken such a line in his own cases, it could be held that in all such conditions the abdomen ought to be opened in order to exclude such an easily curable condition as obstruction by band.

\section{Prognosis.}

The immediate prognosis in these cases must depend largaly on the degree of compression to which the duodenum is subjected, and this can only be estimated indirectly. One factor in this estimation will be the degree of gastric stasis as revealed by radiographic evidence and by careful observation of the relationship to past meals of material vomited. Another will be the child's 
CHRONIC DUODENAL ILEUS

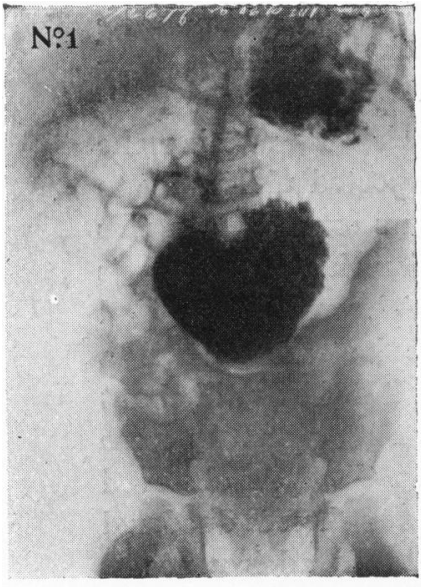

5 minutes, prone.

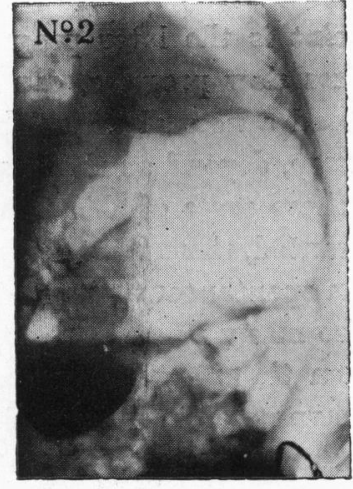

$1 \frac{1}{2}$ hours, erect.

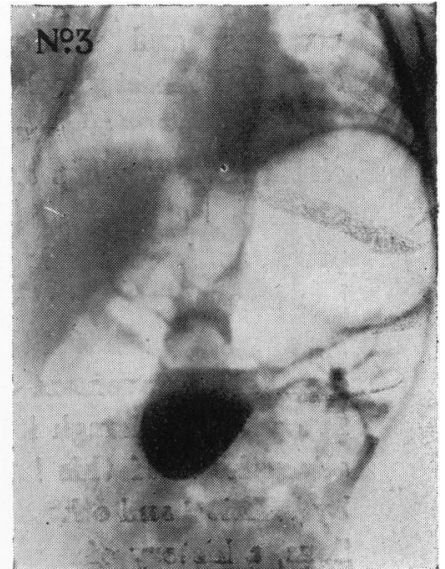

$1 \frac{3}{4}$ hours, erect.

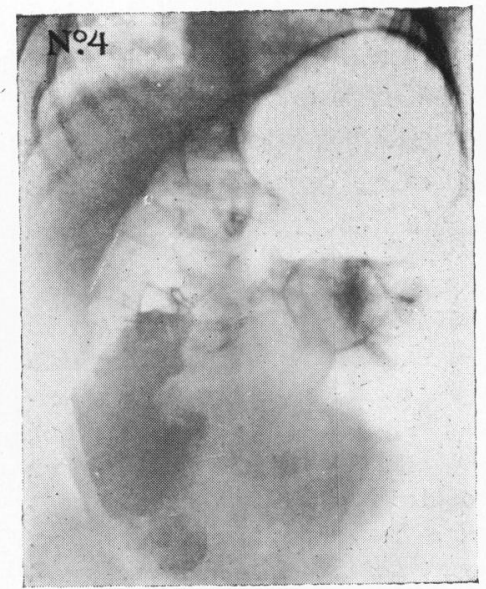

8 hours, prone.

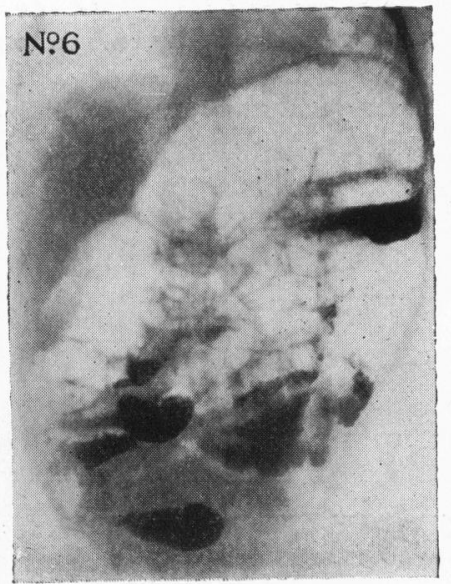

36 hours, erect.

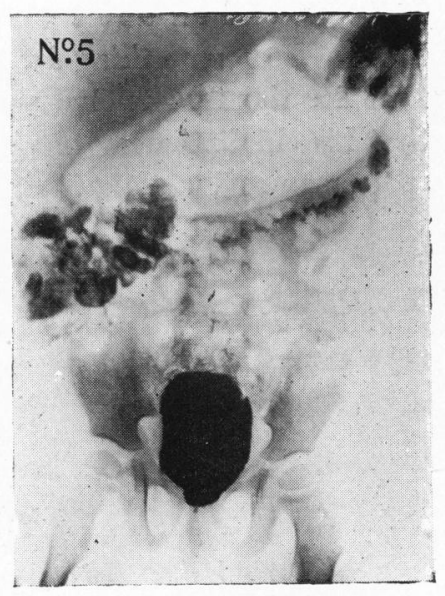

24 hours, prone.

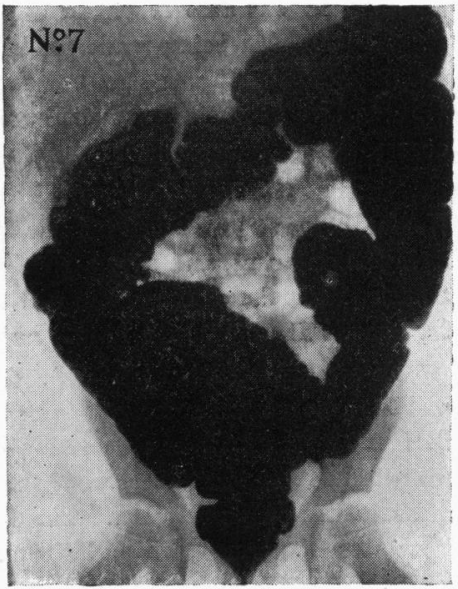

Barium enema, supine. 
capacity to develop gastric hypertrophy, and this will depend on its nutrition, progress, and freedom from intercurrent diseases. The development of atony of the stomach makes the outlook infinitely worse.

The most interesting point is the later prognosis, that is, whether the child, if it survives and makes slow progress, can be expected ultimately to outgrow its symptoms and lead a normal life. The views expressed on this point, as the writer is well aware, depend on the assumption that the diagnosis has been correctly made in those cases of this series which were not verified by operation : but if this is granted, there is no doubt that the tendency is for a gradual improvement to set in spontaneously some time after the age of about five years, although it may be many years before the vomiting attacks cease altogether. If this is so, then these cases correspond to the type observed by Wilkie ${ }^{22}$ and others, who have noted in their adult cases of chronic duodenal ileus, a history of symptoms during childhood passing away in adolescence.

In connection with this point the following case is of interest. It is not included in the present series as the patient was not seen until the age of 29 years, and all direct evidence of obstruction to the duodenum is lacking. It must be a rare thing for a child to suffer from vomiting of the obstructive type for the first twelve years of life (and the patient's own statement was that his chief memory of his boyhood was 'being sick'), and then to recover spontaneously, and it is difficult to suggest any other organic condition to account for such a story except the type of chronic duodenal ileus described here.

P.K., male, aged 29 years. Born at full term, weighing $7 \frac{3}{4} \mathrm{lb}$. Vomiting began at 10 weeks and continued with some diarrhœa and wasting until he was 4 months old. Then with gastric lavage it ceased, but at 5 months it began again. At this time refusal of food was very noticeable, and later became extreme. The mother described the difficulty in getting him to take food as 'incredible': ho never got hungry however long he was starved, and if food were pressed on him he was sick. The vomiting was preceded by pain, and occurred chiefly in the eveninge or at night. Hiccup was persistent, and the child habitually cross. The bowels tended to be loose. He took no solid food until he was 2 years old. His abdomen was large. He did not walk well until he was 5 years old, and at that time had the appearance of a child of 3 years.

At 5 years he began to improve, the vomiting growing less, though still considerable. From $7 \frac{1}{2}$ to 10 he was able to attend day-school. At 10 he went to a preparatory boarding-school, special provision being made for him to have his meals under supervision as they took from $1 \frac{1}{2}$ to 2 hours. He was then being sick about four times a term, but at 12 the vomiting ceased. He was kept at the same school until he was 17 owing to his frailty and small size. Pukerty occurred at 19.

Seen at the age of 29 years, he was frail and light in appearance, and $5 \mathrm{ft} .1 \mathrm{in}$. in height. His father was $5 \frac{1}{2}$ feet, and his one brother the same. His mother was $5 \mathrm{ft} .1 \mathrm{in}$. He earned his living as an artist, and living mainly in the country contrived to keep well. He complained of transient attacks of dyspepsia of the gastric atonic type, and was seldom free of this trouble for long. There was no longer any vomiting.

X-ray examination (H.C.G.). The stomach was of good tone, peristalsis was well marked, and the emptying time normal ( 3 hours). The duodenal cap filled and emftied well. At 4 hours barium had reached the descending colon. At 20 hours the cæcum was filled. The cæcum was placed high, being at the level of the iliac crest in the prone and vertical positions. This might indicate incomplete rotation. The colon was probably rather larger than normal. The pituitary fossa was of normal size and shape. 
The improvement in these cases which occurs so slowly can be hastened in some instances by medical treatment, but it is essentially a spontaneous improviement. The explanation of it is necessarily a matter of speculation. It is clearly not due merely to the development of an adequate compensatory hypertrophy of the gastric musculature. It is apparently the result of normal growth on the part of the child which eases the constriction at the duodenojejunal flexure.

As regards the possible dangers of the supervention of acute symptoms in these chronic cases, it has already been pointed out that the acute type of duodenal ileus does not seem to arise in children. Several of the cases of the present series had had operations performed under anæsthetics without the development of acute symptoms.

The outlook following operation for the relief of the obstruction in these cases is discussed in the section on treatment.

\section{Treatment.}

The factors underlying the treatment of these cases are as follows:(1) there is chronic duodenal obstruction which will in the course of years lessen and disappear; (2) it is sufficient to produce chronic gastric stasis and gastritis ; (3) it can be increased to the point of producing vomiting by distension of the stomach and possibly of the colon; (4) there may be occasional interference with fat-absorption owing to the obstruction to the flow of bile from the duodenum.

Medical treatment. The chief indication is to give a diet which is small in volume, highly nutritious, not too rich in fat, and calculated to pass out of the stomach as quickly as possible. A pounded or sieved mixed diet suits these requirements best, and it should be given as dry as can be made palatable for the child. Meals should be separated from each other by as long intervals as possible. Drinks should only be given some hours after food. It is usually necessary to give lightly skimmed milk or to make use of a halfcream milk. Vichy water is useful as a drink or as a diluent to milk.

To prevent fermentation of the stagnant gastric contents, an alkaline antiseptic, such as glycothymoline in 15-minim doses, is of value. It may be given with a mixture of rhubarb and soda, using peppermint for a carminative. At times when the signs of gastritis have lessened, an acid mixture containing nux vomica may help the appetite. Castor oil has proved the most useful apericnt in small children, and taxol tablets in older ones. If the intestine becomes distended, the colon should be washed out and measures taken to reduce the distension as soon as possible. The chief cause of intestinal distension seems to be fat indigestion. Gastric lavage and massage may be required.

Postural treatment has not the same value in these cases as in adults owing to the fact that they are not connected with visceroptosis in children. In Case 1, during the $\mathrm{X}$-ray examination it was thought that the stomach emptied best in the prone position. 
Surgical Treatment. As spontaneous improvement seems to set in after about the age of five years, surgical measures need only be considered in the severest cases in the younger children. Possibly in some older children lack of progress might persist owing to the development of a secondary atonicity of the stomach, but such cases would not be favourable for gastro-enterostomy.

In this type of case the enlargement of the duodenum is not sufficient to render a duodeno-jejunostomy a practical possibility, especially in a young, small and frail child. The alternative operation is that of gastro-jejunostomy. With an obstruction as low down as the duodeno-jejunal flexure this operation is at a disadvantage, and in adult cases of chronic duodenal ileus it has not been a success and has been abandoned in favour of duodeno-jejunostomy. It may be that in the congenital type of case described here it is too much to expect that any operation for the relief of obstruction will have the same happy and immediate effect as in an acquired obstruction. It must be remembered that these children have never, in the worst cases, looked upon food except with extreme distaste, and it is not a question of restoring a lost appetite but awaiting the development of a new faculty.

On these grounds it is clear that a gastro-enterostomy is to be regarded as the last resort, if all other measures have failed : and that lack of tone in the gastric musculature would be a still further contra-indication to the operation. From the experience of the two cases operated on in the present series it is possible to say that gastro-jejunostomy may be of use. In Case 1, where the tone of the gastric muscle was good, there is no doubt that the condition was alleviated, although the child's progress was slower than had been anticipated at the time of the operation. In Case 2 there was so much gastric atony that the possibility of benefit from gastro-jejunostomy was slight. On the whole the writer would not very willingly consent to operation on cases of this type unless something better than a gastro-enterostomy could be undertaken; yet it seems clear that in very severe instances such an operation may benefit the child at least sufficiently to prevent the development of gastric atony behind the unrelieved obstruction.

Ablation of the pylorus, either at the time of the gastro-jejunostomy or later, has been stated by Downes (see Appendix B) to be of value. This is an operation which cannot be lightly undertaken in a small child, and it is not easy to see on what grounds it should be of benefit.

It is perhaps worth while mentioning here, since gastro-jejunostomy is so seldom performed in small children, that at any time after the operation a fatty feed such as full-cream milk, given on an empty stomach, may cause an immediate vomit of bile and mucus, evidently an evacuation of the gall-bladder and liver. Such an incident is followed later by the passage of a colourless stool.

\section{Summary and conclusions.}

Acute duodenal ileus does not appear to occur in children.

A summary of the previously published work on chronic duodenal ileus in children is given. 
A series of cases showing enlargement and hypertrophy of the stomach (gastromegaly) is described. In them the symptoms date from birth or early life, and consist at first more of anorexia than of vomiting. Other symptoms are malnutrition, lack of growth, hiccup and borborygmus, mucus in the fæces from the presence of chronic gastritis, and occasional fatty stools. A peculiar feature is the comparative lack of pain in the abdomen except immediately preceding vomiting. Thus, the symptoms do not very readily raise the suspicion of organic obstruction to the evacuation of the stomach, but careful examination reveals the presence of obstruction, and skiagrams show that this does not arise in the stomach itself. Hence a diagnosis of gastromegaly from chronic duodenal obstruction is reached, and reasons are given for the view that the cases described owe their origin to chronic duodenal ileus.

There is in these cases a tendency for spontaneous improvement to occur during the later years of childhood. This recalls the fact which Wilkie and others have noted, that adult cases of chronic duodenal ileus may give a history of symptoms during childhood which pass off for many years during adolescence.

Other causes of gastromegaly from chronic duodenal obstruction are discussed.

In acknowledgement of help received in the preparation of this paper sincere thanks are returned to Dr. G. F. Still, Dr. R. C. Jewesbury, Mr. L. E. Barrington-Ward, Mr. C. E. Shattock, Dr. H. Perkins, Dr. A. Moncrieff, Dr. R. K. White, Dr. Maud Sanderson. Dr. H. M. Raven, Dr. G. Elder, Dr. H. G. Broadbridge, Dr. Mary Davies; and to Miss Grace Kendall.

\section{REFERENCES.}

1. Rokitansky, C., Handb. d. spec. path. Anat., Vienna, 1842, II, 215.

2. Rokitansky, C., Lehrb. d. path. Anat., Vienna, 1863, III.

3. Heschl., R., Compend. d. path. Anat., Vienna, 1855.

4. Glénard, F., Lyon medical, Lyon, 1885, XLVIII, 449.

5. Glénard, F., Presse med. belge, Brux, 1889, XLI, 57.

6. Kundrat, H., Wiener med. Wchnschr., Vienna, 1891, XLI, 352.

7. Albrecht, P. A., Virchow Arch. f. path. Anat., Berlin, 1899, CLVI, 285.

8. Petit, L. A., Thése Fac. d. Paris, Paris, 1900, 67.

9. Duval, P., Roux, J. C., and Béclère, H., The Duodenum, Eng. Trans., Lond., 1928.

10. Robinson, B., Amer. Pract. \& News, Louisville, 1900, XXX, 124.

11. Robinson, B., Lancet-Clinic, Cincinnati, 1900, XLV., 577.

12. Finney, Johns Hopkins Hosp. Bull., Baltimore, 1906, XVII, 37.

13. Barker, L. F., Loc. cit., 37.

14. Bloodgood, J. C., Ann. Surg., Philad., 1907, XLVI, 736.

15. Stavely, A. L., Johns Hopkins Hosp. Bull., Baltimore, 1908, XIX, 252.

16. Stavely, A. L., Surg. Gynec. Obstet., Chic., 1910, XI, 288.

17. Bloodgood, J. C., J. Amer. Med. Ass., Chic., 1912, LIX, 117.

18. Kellogg, E. L. \& W. A., Ann. Surg., Philad., 1921, LXXIII, 578.

19. Higgins, C. C., Arch. Surg., Chic., 1926, XIII, 1.

20. Wilkie, D. P. D., Brit. J. Surg., Bristol, 1921, IX, 204.

21. Wilkie, D. P. D., Brit. Med. J., Lond., 1922, ii, 1219.

22. Wilkie, D. P. D., Amer. J. Med. Sci., Philad., 1927, CLXXIII, 643.

23. Barton, J. A. G., Trans. R. Med.-Chir. Soc. Glas., Glasgow, 1929 XXII, 143

24. Leveuf, J., Rèv. de chir., Paris, 1920, LVIII, 616. 
25. Grégoire, R., Bull. et mém. Soc. de chir., Paris, 1920, XLVI, 786.

26. Gracie, J., Trans. R. Med. Chir. Soc. Glas., Glasgow, 1929, XXII, 147.

27. Hayes, R., \& Shaw, A. B., Radiology, Chic., 1929, XIII, 245.

28. Bernheim-Karrer, O., Corr.-blatt f. Schweiz. Aerzte, Basel, 1904, XXXIV, 257.

29. Frank, E. S., Ztschr. f. Kinderh., Berlin, 1913, IX, 99.

30. Downes, W. A., Ann. Surg., Philad., 1917, LXVI, 436.

31. DuBose, F. G., Surg. Gynec. Obstet., Chic., 1919, XXIX, 278.

32. Jewesbury, R. C., Proc. R. Soc. Med., Lond., 1922, XVI, (Sect. Dis. Child.), 10.

33. Henske, J. A., \& Best, R. R., Amer. J. Dis. Child., Chic., 1928, XXXVI, 1224.

34. Higgins, T. T., \& Paterson, D., Arch. Dis. Child., Lond., 1926, I, 285.

35. Variot, G., \& Cailliau, Bull. et mém. Soc. méd. d. hôp. de Paris, Paris, 1922, XLVI, 1.53.

36. Hohlbaum, J., Zentralb. f. Gynak., Leipsic, 1924, XLVIII, 1512.

37. Duval, P., Arch. d. mal. de l'app. digestif, Paris, 1924, XIV, 197.

38. Quain, E. P., Ann. Surg., Philad., 1920, LXXII, 604.

39. Quervain, F. de, Clin. Surg. Diagnosis, 4th Eng. Trans., 1926, 452.

40. Ombrédanne, L., Bull. et mém. Soc. de chir., Paris, 1919, XLV, 688.

41. Wheelon, H., J. Amer. Med. Ass., Chic., 1921, LXVII, 1404.

42. Foucar, H. O., M. Clin. N. Amer., Philad., 1923, VII, 81.

43. Waugh, G. E., Proc. R. Soc. Med., Lond., 1928, XXI, (Sect. Dis. Child.), 79.

44. Judd, E. S., \& White, R. B., Ann. Surg., Philad., 1929, LXXXIX, 1.

45. Miller, R., Brit. J. Child. Dis., Lond., 1923, XX, 88.

46. Sheldon, W., \& Ogilvie, A. G., Arch. Dis. Child., Lond., 1929, IV, 347.

47. Cowell, E. M., Quart. J. Med., Oxford, 1911-12, V, 401.

48. Cautley, E., Brit. J. Child. Dis., Lond., 1919, XVI, 65.

49. Cameron, H. C., Brit. Med. J., Lond., 1925, i, 765.

50. Sheldon, W., Arch. Dis. Child., Lond., 1926, I, 279.

51. Smellie, J. M., Brit. J. Child. Dis., Lond., 1924, XXI, 192.

52. Keith, A., Brit. Med. J., Lond., 1910, i, 303.

53. Koos, A. v., Jahrb.f. Kinderh., Berlin, 1920, XCII, 240.

54. Buchanan, G., Trans. Path. Soc. Lond., Lond., 1861, XII, 121.

55. Silcock, A. Q., Ibid., 1883-84, XXXV, 207.

56. Moore, N., Loc. cit., 202.

57. Perry, E. C., \& Shaw, L. E., Guy's Hosp. Rep., Lond., 1893, L, 171.

58. Curling, E. R., Brit. Med. J., Lond., 1910, i, 435.

59. Terry, W. I., \& Kilgore, A. R., J. Amer. Mled. Ass., Chic., 1916, LXVI, 1774.

60. Rixford, E., Ann. Surg., Philad., 1920, LXXII, 114.

61. Dott, N. M., Brit. J. Surg., Bristol, 1923-24, XI, 251.

62. Poynton, F. J., Lancet, Lond., 1924, i, 1045.

63. Denzer, B. G., Amer. J. Dis. Child., Chic., 1922, XXIV, 534.

64. Duval, P., \& Gatellier, J., Arch. d. mal. de l'app. digestif, Paris, 1921, XI, 145.

65. Bird, C. E., Ann. Surg., Philad., 1929, LXXXIX, 12.

66. Anderson, J. H., Brit. J. Surg., Bristol, 1922-3, X, 316.

67. Moncrieff, A., \& Payne, W. W., Arch. Dis. Child., Lond., 1928, III, 257. 


\section{APPENDIX A.}

\section{Glinical reports of present series of cases.}

Case 1. B.R., male, born February, 1926. 8th child in family of 8 : all other children particularly strong. Born at $8 \frac{1}{2}$ months : birth weight $5 \frac{1}{4} \mathrm{lb}$. From birth it was noted that he was frail and of feeble musculature.

During his first year he was not regarded as an ill child, but there was throughout great difficulty in getting him to take his bottles : it appeared as though he "would not be bothered to take his feeds.' The amounts taken were very small and he displayed no appetite even for the beginning of his bottles. He remained small with flabby muscles. At the end of the first year he weighed $14 \frac{1}{4} \mathrm{lb}$. There was no vomiting of significance at this time.

During the second year vomiting began to become troublesome. The first attack of any severity occurred at 13 months, but such attacks only became frequent after the age of 18 months. Careful observation during the ensuing months showed that vomiting occurred when attempts were made to increase the amount of food taken. The child took, even with difficulty, very small and inadequate meals, and when by pressure he was made to take more, the refusal of food would increase, the tongue would become more than usually coated, hiccup would be persistent, and after a few days, unless the diet were materially decreased in amount, a bout of vomiting would occur. The sickness usually started at night, preceded by discomfort or actual pain, the vomit being large in amount and projectile in type, and containing food and much mucus which was often bile-stained. During the attack of vomiting there was considerable toxæmia, with fever and rapid loss of weight from dehydration. The vomiting was quickly followed by diarrhœa with much mucus in the stools.

At 13 months scoliosis from muscular atony first appeared. This increased considerably in spite of the fact that the child was kept off his feet and did not walk until he was 26 months old. At 13 months he had 9 teeth, dentition being complete by the 26 th month. At the end of his second year he weighed $18 \mathrm{lb} .10 \mathrm{oz}$.

During the third year the condition remained much the same. There was no increase in the amount of food which could be taken, so that the supply become increasingly inadequate for the child's growth.

The boy had been under the care of pædiatricians all his life and was first seen by the present writer in consultation in July, 1928, as a possible case of cœliac disease. He was then 2 years and 4 months old, and weighed $18 \frac{1}{2} \mathrm{lb}$. His height could not be taken owing to the scoliosis. It was noticeable that his complexion was beautifully pink, showing neither toxæmia nor anæmia. His limbs were very small and flabby; his buttocks atrophic. The abdomen was enlarged but chiefly in the upper part, and above the level of the umbilicus gastric peristaltic waves could be seen travelling from left to right across the abdomen. These had not been previously noted. Gastric splashing was easily elicited. Readings of the blood fat had been taken and were accounted high, $(1 \cdot 17,1 \cdot 15$, and $1.51 \%)$. $^{*}$ The child was already on a low-fat diet, and analysis of the stool showed the percentage of fat to be $10.4 \%$. The protein and fat appeared to be well digested, the starch of the food was less successfully digested.

First X-ray examination. In order to investigate the condition of the stomach a liquid opaque meal was given. This, although it demonstrated considerable enlargement of the stomach, failed to show any gastric stasis. The outlet of the stomach was not seen, being hidden behind the enlarged body of the organ. The diagnosis of cœliac disease was therefore set aside in favour of one of general enfeeblement of digestion, especially of vegetable starch. The presence of the visible gastric peristalsis remained unexplained.

The boy was not seen again until December, 1928, when he came under the care of the present writer. His condition was then much the same as it had been six months before. His weight was $19 \mathrm{lb} .7 \mathrm{oz}$. Gastric peristalsis could be seen after meals, and at other times there was much splashing in the stomach. The conclusion was therefore reached that there was obstruction to the emptying of the stomach which was of real moment, but that it came into

* Permission has kindly been granted to mention that this case (B.R.) figures in Table Ir of the paper on the blood fat in cœliac disease by Moncrieff and Payne. ${ }^{67}$ 
play chiefly, or perhaps only, when the stomach was distended. It was clearly necessary to obtain a radiographic picture of the exit of the stomach, and as in the first $\mathrm{X}$-ray examination the pyloric region had been completely hidden by the enlarged body of the stomach, it was determined to reduce gastric distension as much as possible before a second radiographic series was taken. To this end the child was placed on a dry diet, with drinks between meals, daily aperient enemata to reduce possible stagnation, and gastric antiseptics to reduce fermentation. With these alterations there was an immediate improvement in the appetite, but this waned after two or three weeks although the feeding never again became quite so difficult as it had been at its worst. It is interesting that at this time, for the first time in his life, the boy would take a cup into his own hands for a drink.

Under this régime the gastric peristalsis was no more seen, splashing became rare, hiccup disappeared, and the child seemed happy and free from discomfort; but he was unable and unwilling to take enough food to allow for growth and development.

Second X-ray examination. (H.C.G.) On February 26th, 1929, the boy being now 3 years old, an opaque meal was given consisting of 2 oz. of Allenburys food, 2 oz. of barium, made up to $8 \mathrm{oz}$. with milk. Of this the child took 6 oz. (Fig. 1).

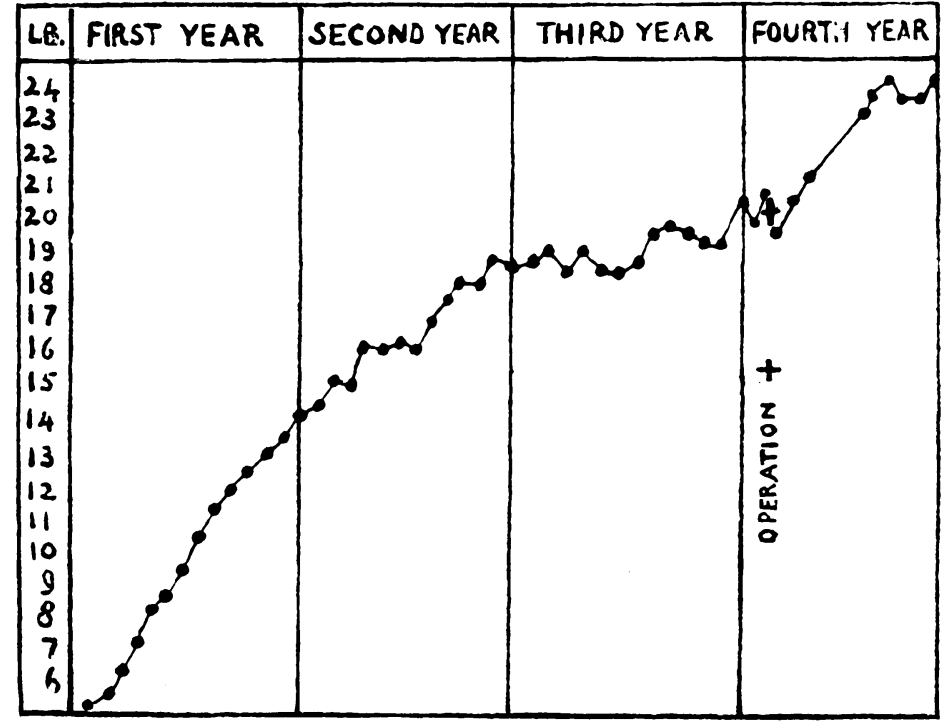

Chart showing weights at 4-weekly intervals in Case 1. The weight becomes stationary in the third year as the amount of food given cannot be increased to meet the increased need of the child.

The stomach was undoubtedly large, but of good tone and showing hyper-peristalsis. It took, however, much longer than the average at this age and with this meal to empty, there being a fasting residue of about $2 \mathrm{oz}$. at $3 \frac{1}{2}$ hours. There was also a residue at $4 \frac{1}{2}$ hours when food was permitted, which accounts for the presence of barium in the stomach in the films taken at 7 hours. The duodenum was judged to be normal, and a lateral view of the stomach and duodenum showed the anterior and posterior surfaces of both stomach and duodenal cap. The distal parts of the duodenum were not seen in any of the films. The passage through the colon presented no unusual features. At 24 hours the cæcum was practically empty, the bulk of the meal being in the transverse colon, sigmoid and rectum.

Manipulation and changes in posture showed that the stomach tended to deviate very much to the right when the child lay on his right side. Possibly the scoliosis facilitated this displacement. It was thought that in this position the emptying of the stomach would be delayed and that the prone position would be the best that could be adopted from this point of view. 
Diagnosis. It was now clear that the delay in the emptying of the stomach was due to some obstruction high up in the alimentary tract. The clinical evidence of this was :- (1) gastric stasis, as shown by splashing, vomiting, hiccup, etc., (2) occasional visible gastric peristalsis, (3) palpation of the thickened gastric wall through the abdominal parietes, (4) presence of chronic gastritis, comparable to that found in the hypertrophic pyloric stenosis of infants, as shown by coated tongue, mucus in the vomit, persistent presence of large collections of sodden mucus in the stools. The second X-ray examination confirmed the presence of enlargement and hypertrophy of the stomach, but gave no indication of the nature or position of the obstruction, except that it was not in the stomach itself.

It was at this time very difficult to decide between two alternative diagnoses. If the obstructive factor were acting persistently, although increased by gastric distension, the diagnosis of duodenal obstruction, intrinsic or extrinsic, appeared most probable. If, on the other hand, the obstruction came into play only when the stomach was considerably distended, it might possibly be due to kinking in an enlarged stomach. Two points favoured the second alternative. First, that the first $\mathrm{X}$-ray examination was taken to show no evidence of any obstruction at all. Secondly, that the only other case which the writer had recognized at that time (Case 7) had improved on measures directed towards preventing over-distension of the stomach.

It was therefore determined to persevere with the régime already described for a further two months, making five months in all. At the end of this time it was found that the amount of food which could be taken showed very little increase; that 3 meals of about $6 \mathrm{oz}$., with a daily ration of more than $12 \mathrm{oz}$. but less than $18 \mathrm{oz}$. of fluid, were all that could be tolerated; that if more than these amounts were given there would develop strenuous refusal of food, hiccup, and the other preludes to an attack of vomiting. Further, the passage of a tube $3 \frac{1}{2}$ hours after a meal still showed a large residue even at the end of 5 months of this strict régime. The boy's weight had slowly increased to $20 \mathrm{lb}$. $12 \mathrm{oz}$, a gain of $1 \mathrm{lb} .5 \mathrm{oz}$. in 5 months.

It therefore became evident that, although it was not certain that the obstruction was persistent, the amount of gastric distension necessary to produce obstructive symptoms was so small that the only hope of progress lay in operation for the relief of the obstruction. At the end of April, 1929, the boy was seen in consultation with Dr. R. Hutchison and Mr. Barrington Ward, both of whom agreed to the wisdom of operation.

Operation. Mr. Barrington Ward operated on May 6th, 1929. The abdomen was opened by a paramedian incision. The stomach was found to be considerably enlarged and its wall definitely hypertrophied. The pylorus was rather wide and dilated. The duodenum was dilated to about the breadth of two fingers : this dilatation affected the first and second parts of the duodenum, and the third part as well, as far as could be determined. The jejunum at the duodeno-jejunal junction was very small and collapsed, and was only about one-third the width of the third part of the duodenum. No definite bands were found at the junction, but the superior mesenteric artery and the mesentery formed a very tight band across the duodenum. The small intestine was small, empty and atrophic, and hung rather low. The transverse colon was normal. The ascending colon was fixed. The cæcum was, perhaps, a little high.

A posterior no-loop gastro-enterostomy was performed. After this was completed the jejunum seemed to be filling up to twice its original size. The abdomen was closed.

The condition found was therefore exactly comparable to the chronic duodenal ileus of adults.

Post-operative Progress. The boy stood the operation well. The stomach was at once reduced in size, its lower border rising towards the epigastrium and feeling extraordinarily hard. The hypertrophy of the gastric wall gradually disappeared, and after many weeks the mucus disappeared from the stools, showing that the gastritis had passed off. Vomiting of food became very infrequent and, as it were, accidental. Thus there was clear evidence that the operation had relieved the obstruction to the evacuation of food from the stomach. On the other hand there were still signs that the flow of bile could be obstructed. At times the fat in the food was not well absorbed and the consequent intestinal distension would sometimes produce vomiting. Further, a fatty feed, such as a drink of full cream milk, given on an empty 
stomach, would sometimes cause almost immediate vomiting of a large amount of bile and mucus, clearly from an evacuation of the gallbladder and liver. After such an event the next stool would be colourless.

Gradually considerable improvement occurred. The child's intelligence began to expand, his memory to improve, and it was noticeable that he responded to a change of air in a way that he had not done before. But the gain in weight was disappointingly slow, although an improvement on the almost stationary weight of the year before the operation (see ('hart), and there was still great difficulty in getting enough food taken. It gradually became clear that the operation was not to be followed by the quick improvement that is the rule in such a condition as an acquired pyloric stenosis.

Four possible handicaps to progress existed. First, the unrelieved obstruction to the flow of bile. Secondly, the psychology of the child. It has to be remembered that the boy had never known what it was to be hungry, nor indeed anything other than extreme distaste for food. Further, owing to under-feeding and under-development, he behaved likean experienced baby, not easily led by reason. Thus he was extremely difficult to persuade to take food properly. Thirdly, poor tissue assimilation owing to the under-feeding which had existed from birth. Fourthly, possible atony of the stomach with gastric stasis persisting in spite of the cperation.

3Ri) X-ray exanination (H.C.G.). In February, 1930, nine months after the operation, a further $\mathrm{X}$-ray examination was undertaken in order to investigate the last point. It was found that a 3-oz. feed of the standard meal was well held up by the gastric muscle and passed rapidly through the stoma. 48 hours later an 8-oz. feed consisting mainly of minced chicken was given. With this meal the tone of the muscle relaxed somewhat and the meal was held for about $2 \frac{1}{2}$ hours, but at the end of this time the stomach completely emptied through the stoma, although the duodenal cap was observed in one film.

This examination, therefore, showed that all the advantage that could be obtained by gastro-jejunostomy had accrued in this particular case, and that the comparatively slow progress depended on the other difficulties inherent in this condition. Doubtless complete recovery will ultimately take place, but it must be concluded that even in such a case as this, where everything seemed favourable and very skilled nursing was available for the child, gastro-jejunostomy does not offer any rapid cure.

Case 2. A.J.E., male, born October, 1924, and first seen (October 3, 1929), at the age of 5 years.

Full term child, weighing $88_{4}^{3} \mathrm{lb}$. at birth. He was breast fed for 2 months. From birth he took his feeds slowly and never seemed ravenous for food, but he progressed well until the 7 th week, when he weighed $121 \mathrm{lb}$. At this time he started to vomit, pumping up his food and crying as if in a good deal of pain. At 10 weeks he was admitted to the Hospital for Sick Children, Great Ormond Strect, London, as a possible case of pyloric stenosis. The following notes on his condition during his stay there have been kindly supplied :-There was no distension of the abdomen, no visible peristalsis, and no palpable pyloric tumour. While in hospital there was some vomiting. Ultimately he gained weight well, though he still vomited occasionally, and after 6 weeks he was discharged with a diagnosis of 'indigestion.' After his discharge he attended for a time as an out-patient and had no more vomiting until he was 6 months old. Then it returned, but not seriously, and he gained well until the age of 10 months. At this age he had measles, followed by some debility, and the vomiting increased, but by giving him small frequent meals he made fair progress until he began to take solid food at the age of 18 months.

From this time his appetite was extraordinarily bad and for days together it was almost impossible to get him to take any food at all. Attacks of vomiting recurred every 3 or 4 weeks, when he vomited two or three times a day and refused allfood. The attacks were accompanied by fever, drowsiness and rapid loss of weight : mucus was present in the stools. After an attack he would eat well for a day. Hiccup was a prominent symptom and might be a prelude to a vomiting attack.

At the age of 5 years he was said to be distinctly worse than he was at 3 , eating even less than he did, and very languid and silent. Ho was thought to be getting thinner although still growing in height. The stools were usually constipated but occasionally large, pale and loose. 
On October 3rd, 1929, he attended the Paddington Green Children's Hospital as an outpatient under Dr. Tallerman who admitted him for investigation under the care of the present writer on October 17 th.

He was then 5 years old and a delicate, frail-looking boy, weighing $34 \mathrm{lb}$. $14 \mathrm{oz}$. He was extraordinarily silent, neither talking nor smiling, but sitting $\mathrm{u} p$ in bed watching. He seemed to be very much the picture of a chronic invalid child. It was impossible to tempt him with any kind of special food, and he took the ordinary diet very poorly. His tongue was coated, and he sat usually holding his stomach as though in discomfort, though there seemed no real pain. The outline of the stomach could be seen under the abdominal wall reaching almost down to the level of the umbilicus, obviously larger than normal. Splashing was easily elicited. The wall of the stomach could be felt through the abdominal wall, suggesting hypertrophy, but no visible peristalsis was at first seen. On distending the stomach with a draught of soda water feeble but definite waves of gastric peristalsis were seen crossing the abdomen; later, peristalsis was seen after feeding without inflation of the stomach. The condition of the stomach suggested one of obstruction with secondary failure of the compensatory hypertrophy. On a diet containing full-cream milk the stools were pale and greasy and contained $59 \cdot 2 \%$ of fat. On a low fat diet this figure sank to $13 \cdot 2 \%$. In both specimens the fæcal fat was adequately split.

X-RaY examination (H.C.G.). On November 7 th an $\mathrm{X}$-ray examination showed a large dilated and atonic stomach, very deficient in peristalsis with much gastric delay, there being a residue of practically half the meal at $3 \frac{1}{2}$ hours. The duodenal cap appeared normal. No evidence of any organic cause for the gastric stasis was discovered (Fig. 2).

Diagnosis. From its similarity to Case 1 it was not difficult to surmise that there was duodenal obstruction from arterio-mesenteric ileus, but that in this case the compensatory hypertrophy of the gastric musculature had failed. As there seemed no chance of getting improvement here and the child's condition has been steadily deteriorating according to the parents' account, it was determined to operate for the relief of the obstruction.

Operation. On November 22nd, 1929, the abdomen was opened by Mr. Shattock in the right paramedian line. A small amount of clear fluid escaped, the origin of which remained unexplained. No signs of tuberculosis were found in the peritoneum, mesentery or glands. The stomach was large, dilated and flabby, but its wall appeared thickened. The duodenum was dilated and hypertrophied, appearing like an adult duodenum. This abnormality was present as far as the duodenum could be traced (first and second parts). The jejunum was normal in size. Two small peritoneal bands or thickenings were found but were not obstructing the bowel : they ran upwards from each side of the pylorus. The colon was ${ }^{-}$distended but was not abnormally movable. The cæcum was not high in position, and the hepatic flexure appeared normal. The condition was taken to be one of chronic duodenal ileus, and a posterior gastrojejunostomy performed.

Course. In the three months following operation only slight progress was made, though periods of increased interest in surroundings, improved appetite and gain of weight were seen. It was evident that, although the stomach had diminished in size since the operation, there was sufficient lack of tone in it to be a serious handicap. The stools at times were fatty, and only half-cream milk could be tolerated. Any distension of the intestine quickly produced vomiting. The psychological state made it very difficult to appreciate the true value of his symptoms. At Christmas, for instance, he eat well and gained weight, but at a visit from his parents he would lapse into complete apathy and silence, and could not (apparently) summon up strength enough even to wave good-bye to them. Thus it was very difficult to judge how much of the refusal of food was due to his mental attitude, and how much to unrelieved gastric stasis from gastric atony.

Case 3. M.M., female, born June 1923. First seen at the age of $5 \frac{1}{2}$ years (December, 1928), referrred by Dr. Elder of Mansfield. Brief notes are available from birth, but weight records of infancy are missing.

Birth weight was $4 \mathrm{lb}$. From birth it was very difficult to get the child to take food properly. In addition there was fairly frequent sickness, the vomit being often definitely projectile. Diarrhœa, with stools containing mucus and sometimes blood, was associated with the vomiting. Of the three symptoms, refusal of food, vomiting and diarrhoea, the most troublesome was the 
first. The taking of food seemed to cause discomfort and so food was obstinately refused. The baby was habitually cross. Hiceup was a prominent symptom. At 3 months her weight was $7 \mathrm{lb} .13 \mathrm{oz}$. After 6 months she began to get a little better, and still further improvement occurred between 18 and 24 months, attributed to the change on to solid food.

Contemporary notes during the $2 \mathrm{nd}$, 3rd and 4 th years constantly refer to the difficulties in getting the child to cat. Graduaily the vomiting settled down into attacks typical of gastric stasis. The sickness would occur in the evening, preceded by increased refusal of food and extra coating of the tongue. The vomit was large, contained mucus and altered food, and the sickness was followed by loose motions containing mucus. During these years growth in weight and height were slow. At 5 years she weighed $38 \mathrm{lb}$.

Finst X-ray examisation. (The nature and the quantity of the meal used are not known.) In November, 1928, an X-ray examination showed a very large stomach covering over the pyloric region. The tone of the stomach appeared normal and peristalsis did not appear to be active at the time when the films were taken. The emptying time of the stomach was, however, only 2 hours.

The girl was first seen on December $28 \mathrm{th}, 1928$. She was then $5 \frac{1}{2}$ years old and weighed $36 \frac{1}{2} \mathrm{lb}$. Her height was $43 \mathrm{in}$. For the last six weeks, following the $\mathrm{X}$-ray examination, she had been placed on a dry diet and had had no vomiting. She had, however, lost $\frac{3}{4} \mathrm{lb}$. On examination nothing abnormal was found except in the region of the stomach. This organ appeared enlarged, splashing was easily obtained, but no peristalsis was seen even after a draught of cold water had been taken. In September, 1929, however, well-marked peristalsis was seen following distension of the stomach by a draught of soda water. The feel of the stomach through the abdominal wall suggested hypertrophy of its walls. The régime of a dry diet was continued and made more stringent.

On March 19th, 1929, the child was seen again. She had continued free of vomiting and had now lost all nausea. Her weight had increased to $38 \mathrm{lb} .12 \mathrm{oz}$., and she had grown $\frac{1}{2}$-in. in height since December.

Second X-ray examination (H.C.G.). At this time a second X-ray examination was made with an opaque meal consisting of $2 \mathrm{oz}$. of Allenburys food, $3 \mathrm{oz}$. of barium, made up to $12 \mathrm{oz}$. with milk. The stomach was regarded as average in size : its tone good and peristalsis suggestive of hypertrophy. The emptying time was normal : at 3 hours only a trace of the meal remained in the stomach. Nothing abnormal was detected in the stomach, and the duodenal cap filled and emptied normally. At 3 hours the meal had reached the middle of the transverse colon. At 7 hours the sigmoid was full, and at 24 hours the whole of the meal had passed. The bowels had acted twice in the interval, although no aperient had been used. The colon appeared average in length and size (Fig. 3). In connection with this result it must be remem. bered that the child had been completely free of all symptoms for 4 months before the X-ray examination was made.

In September, 1929, the girl was seen again. She was now 61 years old : weight $38 \mathrm{lb}$., and height $44 \mathrm{in.}$ She had had an attack of scarlatina which had delayed progress, but there had been no vomiting at all. Her appetite showed distinct improvement. By administering a draught of soda water well marked gastric peristalsis became visible.

In March, 1930, her weight was $42 \frac{1}{2} \mathrm{lb}$, and her height $45 \mathrm{in}$. She had had whoopingcough and chicken-pox. She had remained free of vomiting; her appetite, though still subnormal, had improved. Visible gastric feristalsis was elicited as before.

1)IAGxosis. In view of the history of the case and its similarity to Cases 1 and 2 it was difficult to doubt that some obstruction was present to the emptying of the stomach. The X-ray examination did not give satisfactory confirmation of this view, probably because spontaneous improvement had already set in. Definite proof of obstruction was ultimately obtained by the production of visible gastric peristalsis after inflation of the stomach by soda water. It is therefore suggested that obstruction was due to chronic duodenal ileus.

Counse. For 16 months on a dry diet there had been no vomiting and the appetite had shown improvement. It was clearly right to continue treatment on the same lines.

Case 4. H.D., male, aged 4 years. Brought for malnutrition and diarrhœa. First seen November 28th, 1928. Lived at Pau. History of the first 11 months of life was not obtainable, 
but at this age he was frail and weighed $14 \mathrm{lb}$. At 2 years he was stronger and until 3 he got on fairly well, but was subject to attacks of diarrhœa, the motions being large, pale and offensive. Since the age of 3 years his progress has been very slight. His diet has had to be rigorously restricted or diarrhœa would supervene. He was regarded as an obscure case of indigestion, and on the restricted diet his appetite was good. There was hiccup but no vomiting.

At 4 years of age he weighed $28 \mathrm{lb}$. and was of normal height, but very frail in appearance. His tongue was thickly coated and his breath foul. His abdomen was large in its upper part and the outline of an enlarged stomach could be clearly seen. The wall of the stomach felt thickened and gastric peristalsis was visible. Splashing could be elicited at any time. Examination of the stool showed that the food was well digested : total fat $-26 \cdot 8 \%$ of the dried frces. The urine was normal except for a great excess of indican.

The boy was admitted to a nursing-home. His diet was increased and he eat readily. He was given pounded food with drinks between meals.

X-Ray examination (H.C.G.). On December lst he was given an opaque meal consisting of $2 \mathrm{oz}$. of Allenburys food with chocolate, made up to $8 \mathrm{oz}$. with milk. The stomach was found to be considerably enlarged, tending to hide the outlet. The tone was good, peristalsis was powerful and in one film suggested hyper-peristalsis. There was a small residue at $3 \frac{1}{2}$ hours. The duodenal cap, seen in the semi-oblique position, was normal, and no abnormality other than the enlargement of the stomach was found. The meal was not traced through the intestine (Fig. 4).

Diagnosis. Mild obstruction to the emptying of the stomach, probably due to chronic duodenal ileus.

Course. During the fortnight that he was under observation the boy gained $3 \frac{1}{2} \mathrm{lb}$., and except for some hiccup he was free of symptoms. He had, however, been previously on an extremely low diet, which accounted for his rapid gain. In the next 14 weeks, at the seaside he gained $4 \mathrm{lb} .10 \mathrm{oz}$.

Case 5. D.M., male, aged 2 years and 4 months when first seen (May 29, 1929). Referred to Paddington Green Children's Hospital for enlarged abdomen by 1)r. Broadbridge, as possible Hirschsprung's disease.

Full term, weighing $8 \mathrm{lb}$ at birth. First tooth cut at 6 months; began to walk at 15 months. Has one sister aged 13 years. He was breast fed at first.

Towards the end of the first year, probably about the 9 th month, the abdomen was noticed to be big. The enlargement tended to increase, but as the boy was quite well except for attacks of bronchitis, he was not taken to any doctor until quite recently. Throughout there has been no vomiting and the appetite has been good, though he required coaxing over his food at times. Weight has been maintained. Bowels regular.

The child was fast asleep when first seen in out-patient department. The upper part of the abdomen protruded and across it were passing large peristaltic waves from under the left ribs to the right. The stomach was enlarged, reaching the umbilical level, and its wall could be felt evidently hypertrophied. Splashing was easily elicited. No tumour was felt.

The boy was admitted and under observation he eat well and was not sick. His weight was $25 \mathrm{lb}$, and his height appeared normal. Visible gastric peristalsis was easily elicited by giving a drink of cold water. The tongue was slightly coated but there was no real evidence of chronic gastritis. The bowe's were regular. The descending colon could ke felt and appeared of normal size.

X-RAY eXamination (H.C.G.). The stomach was much enlarged. Peristalsis was vigorous and indicative of hypertrophy of the gastric wall. More than $50 \%$ of the meal remained in the stomach at the end of $3 \frac{1}{2}$ hours. The duoderal cap appeared normal. The colon was distended and perhaps large (Fig. 5).

Diagnosis. The presence of an enlarged and hypertrophied stomach is clearly proved clinically and radiologically in this case. As before, there is no evidence to show where the obstruction occurs, and it is suggested that it is due to chronic duodenal ileus.

Course. As the boy showed no symptoms and was making good progress he was discharged on June 12 th without treatment, 
Case 6. A.A., male, aged 6 years. First seen November 15th, 1929, on account of attacks of bronchial asthma which have recurred since he had broncho-pneumonia at the age of 8 months. He walked at 18 months. Tonsils and adenoids removed at 2 years.

On examination the upper abdomen was seen to be protuberant, the outline of the stomach was clearly visible, its wall could be easily palpated, and well-marked waves of gastric peristalsis were passing across the upper abdomen. After this observation the following facts were elicited :

The boy's appetite had always been rather poor, and had been worse since the change on to solid food at 18 months. His appetite had now become very bad and for the last two years there had been a loss of weight. There were periods of refusal of food and nausea, but vomiting was only occasional. When it occurred the vomiting was projectile. The boy stated that he felt very full after his meals and had a lot of flatulence. Hiccup occurred daily after food and was very persistent. About an hour after meals there was much gurgling in the stomach. The bowels tended to be loose rather than constipated.

The boy was admitted the same day to Paddington Green Children's Hospital. His weight was $43 \mathrm{lb}$., and his height appeared normal. His body was very thin but his muscles good. The chest showed some catarrhal sounds. The sputum and fæces contained no tubercle bacilli. On an ordinary diet gastric peristalsis of a powerful type was visible on many oceasions, and the stomach felt hypertrophied. Splashing was persistently present. His appetite was not good but there was no real refusal of food. The stool on ordinary diet showed that the food was well digested: fæcal fat $-22 \%$ of dried fæces.

X-RAY EXamination (H.C.G.) (November 21st.) Stomach was only a little larger than normal. Peristalsis was very vigorous soon after the ingestion of the meal, but later failed. There was much gastric delay showing a large residue in the stomach at 433 hours. No view of the duodenal cap was obtained. The condition found indicates one of mild obstruction with gastric hypertrophy and hyper-peristalsis (Fig. 6).

Diagnosis. Mild obstruction probably due to chronic duodenal ileus.

Course. The boy was given a diet consisting of pounded and minced foods taken as dry as possible, with long intervals between meals. Drinks were taken in between meals. The foot of the bed was kept raised. On this régime the stomach became less obvious and the gastric peristalsis was much less in evidence. A small amount of weight was lost. He was discharged on December 11th, 1929.

Case 7. E.McC., male, aged 8 years. First seen January 6th, 1926. This was the first case seen by the writer showing visible gastric peristalsis in childhood. He was brought up for poor digestion.

He had always been a very poor feeder. In infancy he was seen by a pædiatrician who kindly reported that there had been no question of hypertrophic pylorie stenosis. Of late his appetite had been improving. He had had no abdominal pain and was occasionally sick. Hiccup was very persistent. The abdomen had been enlarged from the age of 18 months to 6 years. The bowels were rather constipated, but about every 2 months the stools became large, pale, and loose.

The boy was $49 \mathrm{in}$. in height, and was pale and thin. His eyes were puffy. The upper abdomen was enlarged and visible peristaltic waves passed from under the left ribs downwards and to the right. Splashing was elicited, proving the enlarged viscus to be stomach. The urine was normal : no indican, some oxalate crystals. Stool contained $20 \%$ of fat.

X-RAY EXamination. (January 13th, 1926.) The stomach was very large hiding the duodenal cap and emptying slowly. Appendix retained barium over 72 hours (Fig. 7 ).

Diagnosis. It was recognized at the time that there was some obstruction to the outlet of the stomach which did not show in the X-ray examination. It was thought that it might be a case of kinking of an atonic stomach. It is now suggested that the obstruction was due to chronic duodenal ileus.

Covrse. Dry meals with drinks in between were ordered. Massage daily to the stomach was given and a mixture of listerine, acid and nux vomica. Seen two months later the improvement in the boy's colour and appetite was satisfactory. He had gained $\frac{1}{2}-1 b$. in weight. The outline of the stomach under the abdominal wall could still be seen, but no visible peristalsis could be produced. 
In April, 1929, the boy, now aged 11 years, was reported as very well, eating ordinary school diet, and weighing $66 \frac{1}{2} \mathrm{lb}$. in clothes. His appendix had recently been removed without incident.

Case 8. J.G., male, aged 12 years. Referred by Mr. Douglas Robertson for misshapen abdomen which it was thought might prevent his entrance into the Navy. First seen July 31, 1929.

The early history of this case was not obtainable. His abdomen was certainly enlarged at the age of 5 years when he had a severe attack of pneumonia. At that time the suspicion of fluid in the abdomen was raised, but no operation performed. Since then he had been in fair health but had suffered a good deal from attacks of vomiting. These now occur about four times a year : the vomitus will contain bile. He is at boarding-school and his general physique is improving, especially since he started regular drilling exercises. His tonsils and adenoids were removed without incident one year ago. The bowels are regular.

On examination the enlargement of the abdomen was all in the uppermost part where the stomach could be seen much distended and giving the abdomen a peculiar outline. Splashing could be obtained but no peristalsis was seen, nor did it appear after a draught of soda water.

X-ray Examination (H.C.G.) On August 3rd, 1929, a 12 oz. opaque meal was given. The stomach was definitely larger than the normal for the patient's size. Peristalsis was normal and the emptying time average. The bulk of the meal had left the stomach in 2 hours. There was no evidence of any abnormality of the stomach except its size, and the duodenal cap was normal. Nothing was found to suggest the cause of the gastromegaly. There was no ileal stasis. The colon was voluminous and the transverse portion long and dipped low in the pelvis when the boy was erect. There was no evidence of any abnormal fixation of any part of the colon. At 24 hours the right half of the colon was emptying and a small quantity of the meal had been passed. There was, however, a definite tendency to stasis, there being a considerable residue at 24 hours. The bowels acted once daily during the examination : no aperient was used (Fig. 8).

DiAgnosis. The evidence of obstruction in this case is not conclusive, but it seems probable that hypertrophy of the gastric wall is present in view of two facts, first, the way in which the stomach could be seen standing up under the abdominal wall, and secondly, the normal emptying time of the very much enlarged stomach. As to the cause of the obstruction it is impossible to incriminate the attack of pheumonia or to suppose the presence of peritonitis at that time. Consequently it is suggested that the case is one of chronic duodenal ileus in which possibly the voluminous colon plays a added part in the production of obstructive symptoms.

Course. Progress being satisfactory, dietetic treatment and the continuance of drill were advised.

Case 9. D.N., female, born May 1st, 1923. Referred by Dr. R. K. White of Southsea for enlarged abdomen. First seen September 2nd, 1925, at the age of 2 years and 4 months.

The abdomen had been getting large for quite a year. In the mornings it measured $21 \frac{1}{2}$ in. in circumference, and at night, in spite of an action of the bowels at 6 p.m., it was usually 25 in. There was much gas in the stomach and intestines. The motions were inclined to bo alternately constipated or loose : they were always of good colour. She appeared to feel quite well, and had a high colour. She eat hungrily the rather restricted diet permitted. She was not thin and was growing steadily in height.

On examination the abdomen was seen to be much distended and tympanitic all over. Megacolon was suspected but no peristalsis of stomach or colon was observed. Urine contained an excess of indican. The fæces showed no excess of fat on a high-protein, low-fat diet : muscle fibres were not well digested.

Seen again in February, 1926, there had been general improvement following a course of colon lavage. On a more normal diet the fæces showed $37 \cdot 2 \%$ of fat.

First X-ray examination. (February 23rd, 1926.) The stomach showed great enlargement containing a great excess of gas. Its emptying time was slightly over the normal. The duodenal cap was not seen. The colon also showed great dilatation, which was confirmed by an opaque enema.

Diagnosis. The enlargement of the colon was taken to be atonic distension secondary to fat decomposition comparable to that noted by the present writer in a case of coliac disease. 
The condition of the stomach was regarded as in some way not understood secondary to the megacolon (Fig. 9).

Course. From this time the girl was kept on a low-fat diet and gradually improved. She kept a good colour, had very pink cheeks and gained in weight and height, and eat well. She was a matter-of-fact little girl, who liked her doctors and enjoyed her X-ray examinations, but without any morbid self-interest. All these points were against a diagnosis of cœliac disease, but on the other hand any extra fat in the diet produced abdominal distension which otherwise was not too great.

Second X-Ray Examination. (March 1928). The stomach and colon were enlarged as before, but their tone was improved. The gastric peristalsis suggested the presence of hyper trophy of the wall of the organ.

On May 29th, 1929, the girl was seen again and the stomach was distended by a draught of soda water. Well-marked peristalsis was seen passing across the abdomen in the gastric region. She was now aged 6 years, weighed $47 \frac{3}{4} \mathrm{lb}$., and measured $44 \frac{1}{2} \mathrm{in}$. in height. Since July 9 th, 1926, she had gained $16 \frac{1}{4} \mathrm{lb}$. in weight and grown $7 \frac{1}{2} \mathrm{in}$.

Diagnosis. It is suggested that the obstruction to the stomach thus tardily recognized is due to chronic duodenal ileus, and that the dilatation of the colon is a factor in the production of the obstruction. The cause of the enlargement of the colon is obscure : it may be due to fat indigestion secondary to the obstruction to the bile in the duodenum. It is unlikely to be the result of cœliac disease of the ordinary type.

\section{APPENDIX B. \\ Recorded cases of chronic duodenal ileus in children.}

Bernheim-Karrer ${ }^{28}$ (1904). Boy aged 8 months at death. Soon after birth he began to vomit breast milk. The vomiting persisted in spite of treatment. Obstinate constipation was also present. He developed frequent convulsions and ultimately died suddenly in his bath. The convulsions were regarded as due to toxic products of decomposition in the stomach and duodenum. During life no examination for visible gastric peristalsis was made.

At autopsy the superior mesenteric artery was found to be compressing the duodenum, and the duodenum above the constriction was so much dilated that it resembled a second smaller stomach.

The author refers to Albrecht's? paper (1899) on duodenal ileus in adults, and states that the case recorded is the first one reported in a child.

Frank ${ }^{29}$ (1913). CASE 1. Girl, first child. Breast-fed for 4 months. Gained in weight until the age of $4 \frac{1}{2}$ months when vomiting started, at first immediately after food, but later once only in the day, independent of food. The vomits became very large and seemed to consist of more than the last feed. Sometimes they were green, but never black. Increasing constipation was present. The mother had noticed excess of gurgling in the abdomen but no enlargement.

When first seen (August, 1911) at the age of 11 months, the child was very much wasted, weighing 4,650 grm. The abdomen was strikingly enlarged in its upper half, and left-to-right peristalsis was clearly seen in the epigastric region. The enlarged stomach could be seen and felt, and to the right of it was a smaller swelling. These could be emptied manually and gave the impression of emptying through a constriction. On passing a stomach tube much air escaped and the epigastric fullness collapsed, the circumference of the abdomen decreasing from $43 \mathrm{~cm}$. to $38 \mathrm{~cm}$. The stomach contents contained bile, free $\mathrm{HCl}$, but no blood. The child took food hungrily but was restless after feeding until a large vomit brought relief. Loud borborygmi were noticed.

After 10 days treatment without progress the abdomen was opened. There was found great distersion of the stomach and duodenum up to the root of the mesentery : on the other side of the mesenteric root the bowel was collapsed. Adhesions were present round the gall-bladder and duodenum. After dividing the ligament of Treitz, duodeno-jejunostomy was performed. 
As a result of the operation the vomiting stopped and the child's weight increased regularly; 18 months later the girl was said to be well-developed and strong, with a normal digestion.

The author in discussing this case regarded it as an example of duodenal ileus in a child.

Case 2. Boy. Healthy during the first year of life and then lost appetite and began to vomit. Vomits were very large, ' 2 meals at a time.' Vomiting stopped after 14 days for several weeks during which time there was a slight increase in weight. The sickness then returned but was followed by another period of quiescence. The circumference of the abdomen was increased.

Boy was first seen (August, 1912,) at the age of 2 years. He was very wasted : weight = 7,300 grm. The upper abdomen was very promineat, and by blowing up the stomach the prominence could be proved to be due to an enlarged stomach. The greater curvature reached down to within 2 finger-breadths of the umbilicus. Further distention could be made out in the region of the duodenum. X-ray examination showed two shadows, the stomach and duodenum, divided by a broad lighter part corresponding to the pylorus. After $1 \frac{1}{2}$ hours none of the meal had passed out of the duodenum. After $4 \frac{1}{2}$ hours a fairly large amount had passed into the bowel, but at 8 hours the duodenum was still well filled. A diagnosis of chronic occlusion due to arterio-mesenteric ileus was made.

Seen 6 months later there had been no further vomiting, and the physical signs remained as before. Operation was recommended and refused.

The author notes that the apparent absence of bile in the vomit in this case is probably to be explained by the loss of colour through dilution.

Downes $^{30}$ (1917). Boy, weight at birth $6 \mathrm{lb}$. Breast-fed for 5 months. Vomiting started almost from birth and got gradually larger in volume. Vomit contained food taken two or three days previously. The sickness would stop at times for periods of one or two months. Attacks of diarrhœa occurred about every two months. Tiney were accompanied by much prostration and the passage of blood and mucus in the fæces.

When first seen at the age of $4 \frac{1}{2}$ years, the boy waighed $29 \mathrm{lb}$. in his clothes. Irregular gastric peristalsis could be seen, and definite duodenal peristalsis, passing from above downwards below the region of the pylorus was also seen. X-ray examination showad the duodenum to be almost as big as the stomach.

At operation the wall of the stomach was found to be thickened. The pylorus easily admitted the tip of the index finger. The duodenum was dilated to almost the size of the stomach and its wall was three or four times its normal thickness. The distension involved the whole of the duodenum, ending abruptly where the gut passed under the superior mesenteric artery. A posterior no-loop gastro-enterostomy was performed and the pylorus closed with silk ligatures. The child did well until the pylorus reopened. Later the pylorus was divided in a second operation and the improvement afterwards was satisfactory.

DuBose $^{31}$ (1919). Female, mongol: weight at birth-7 $7 \frac{1}{2}$ lb. Began vomiting yellow fluid on the third day. At 2 months was seen by author for vomiting. Weight then $=5 \frac{1}{2} \mathrm{lb}$. Pyloric stenosis was excluded on account of the presence of bile in the vomit, the absence of palpable tumour, and the X-ray examination which showed megaduodenum. On opening the abdomen it was observed that the duodenum was of enormous size, dilated and flaccid. There w. s neither diverticulum, constriction, adhesive band, nor kink of the duodenum, but the jejunum was collapsed beyond its origin at the mesentery, having an appearance such as is found in mechanical obstruction of the intestine caudal to the point of otstruction. 'It is probable that in this case we have a true arterio-mesenteric obstruction at the duodeno-jejunal flexure of congenital origin . . rather than a congenital giant duodenum.'

Jewesbury ${ }^{32}$ (1922). Male, aged 9 days. From the 3rd day of life projectile vomiting and wasting developed. Slight jaundice was present. Gastric peristalsis was visible. Feeds gave rise to discomfort : vomits were large, forcible and bile-stained.

At autopsy the stomach and duodenum were enormously dilated and hypertrophied. Below the duodeno-jejunal junction the bowel was very shrunken and small. The cæcum was abnormally high and under the liver. The obstruction in the duodenum was caused by pressure from outside by surrounding structures, and in particular the right colic artery.

Henske and Best ${ }^{33}$ (1928). Child weighing at birth $8 \mathrm{lb} .1 \mathrm{oz}$. Vomiting started from birth and was accompanied by locse motions. At 5 months its weight was $11 \mathrm{lb}$. At this time 
a diagnosis of pyloric stenosis was made. An X-ray showed gastric stasis and dilated duodenum, but the latter 'was overlooked at the time.' Under treatment the child improved and at 12 months weighed $21 \mathrm{lb}$. At 13 months there was fresh vomiting, the vomit being green fluid mixed with food. The bowels were again loose. Recovery ensued, but at 21 months the baby died in another similar attack.

At autopsy the cæcum was found in the middle line just behind the umbilicus, and the large intestine was not anchored. "There was definite partial obstruction at the duodeno-jejunal angle, caused not only by the twisting and fixation of the jejunum on its longitudinal axis . . . but also by the dragging of the transverse colon. The mesenteric root was also compressing the jejunum. Naturally, the loaded ascending and transverse colon increased the obstruction more than the empty colon, and permitted attacks of duodenal toxicosis, which resulted in vomiting and dehydration.'

Quervain ${ }^{39}$ (1907). Girl, aged 13 years, the subject of disease of the cervical spine and compensatory lordosis in the lumbar region. The stomach and the duodenum, which, as operation showed, reached considerably to the right, were greatly distended, and gave evidence of splashing on auscultation. The stomach was tympanitic and the duodenum yielded a metallic note. The cervical disease prevented the use of the knee-elbow position for the purpose of treatment, and the fact of tuberculosis did not, of course, exclude obstruction by a band. Laparotomy was, therefore, performed and showed the whole of the small intestine deeply in the true pelvis. The kink was situated at the junction of the duodenum with the jejunum. The latter became filled with gas as soon as it was lifted up.

Quain $^{38}$ (1920). Girl aged 17 years. Stated to have been quite well until she was 8 years old. She then started to have pain in the stomach immediately after food and lasting $\frac{1}{2}$ to 1 hour. Often this was associated with the vomiting of bile which give partial relief for a day. After about 4 years the pain and vomiting were less constant but would occur at least once a week. Her appendix was removed at 14 without relief. For 3 months before coming under the care of the author the pain had been much worse, occurring after each meal and before breakfast. Bile was vomited almost daily. Severe constipation was present: laxatives led to increase in the pain. The girl complained of almost constant dull headache.

At 17 the girl was small, thin and pale. X-ray examination showed enlarged stomach with ptosis nearly to the pubes. Delay in the second part of the duodenum was observed. The gastric juice was practically normal.

At operation a membrane running from the descending duodenum to the liver at the right of the gall-bladder was found. No glands were present. The third part of the duodenum was much dilated and formed a ' $U$ ' with its angle reaching to nearly the pelvic brim, and its distal end passing upwards to the superior mesenteric artery. This ascending part was over 2 inches in diameter and showed thickening of its wall. The dilatation of the gut ended abruptly at the superior mesenteric artery in an abnormally narrow jejunum. 'It was clear that the constriction had been chronic enough to cause both dilatation and hypertrophy of the duodenum.

Duodeno-jejunostomy was performed and gave complete relief to the patient. She gained $30 \mathrm{lb}$. in weight in 3 years.

Higgins $^{19}$ (1926). Boy, aged 7 years, had had for several months epigastric pain which at times was severe. Vomiting occurred in attacks. Constipation was present. X-ray examination revealed an incomplete obstruction at approximately the point where the superior mesenteric artery crossed the spine. Above this point the duodenum was dilated and reverse peristalsis was present. A diagnosis of dilated duodenum was made. Improvement occurred under treatment by means of a special diet and the use of an abdominal binder.

Wilkie $^{22}$ (1027). In a series of 75 cases of chronic duodenal ileus the youngest patient was a boy aged 7 years. The only account of this case is as follows :- The most marked case of duodenal ileus with which $I$ have met was that of a boy aged 7 years, in whom, owing to an abnormal rotation of the bowel, the duodenum was twisted sharply around the mesenteric vessels with resultant recurring attacks of complete duodenal obstruction which brought him frequently to the point of death. These attacks were finally stopped by short-circuiting the bowel around the difficulty. 


\section{CHRONIC DUODENAL ILEUS}

Ombrédanne $^{40}$ (1919). Girl aged 12 years who had suffered since she was 18 months old from bilious vomiting occurring two or three times a month. Gastric peristalsis was observed and a duodenal tumour detected. Tetany was present. At operation there were found arteriomesenteric compression together with volvulus. The volvulus was put right and colopexy performed.

Wheelon ${ }^{41}$ (1921). Baby of 7 months who had had 'gastric disturbance' since birth. For one week had had bilious vomiting, constipation and emaciation. X-ray examination showed megaduodenum, suggesting kinking of the small intestine about the region of the ligament of Treitz, or at the point of emergence of the duodenum from its retro-peritoneal position. Operation discovered a mass in the left side of the pelvis which showed small intestine in a sac of peritoneum, and had slipped through an opening in the root of the mesentery, thought to be congenital. The mass was reduced, and the mesenteric slit sewn over. The child died.

During life no visible gastric peristalsis was noted, but waves of peristalsis were seen which were taken to indicate obstruction of the terminal portion of the duodenum or upper part of the small bowel.

Foucar ${ }^{42}$ (1923). Boy aged 4 years. Suffered from pulmonary fibrosis and bronchiectasis resulting from whooping-cough. Since 1 week old he had been subject to attacks of vomiting three or four times a year, each attack lasting two or three weeks. During them he vomited 2 to 10 times a day without relationship to meals. The vomit was copious in amount and projectile in character, at first containing some food but later greenish mucoid material only. With the attacks were some fever, and pain in the umbilical region. He was admitted to hospital for a plastic operation on the chest.

At 4 years he weighed $27 \mathrm{lb}$. Under observation the outline of the enlarged stomach was seen extending below the level of the umbilicus, and definite gastric peristalsis was seen. An X-ray examination made during a quiescent period showed no evidence of obstruction in the stomach or duodenum : the colon was somewhat dilated. Later, during an attack of vomiting, the examination was repeated and then revealed obstruction to the duodenum about $15 \mathrm{~cm}$. from the pylorus.

At operation the duodenum was found dilated as far as the upper jejunum. The small intestines were matted together by dense adhesions and had become twisted. This volvulus, through the bands of adhesions, closed the lumen of the duodenum also. The volvulus was unfolded and the adhesions freed. Six months later the child was reported as well and having gained much weight. "It was concluded that the child was suffering from adhesive fœetal peritonitis, resulting in a volvulus of the small intestines which closed the lumen of the duodenum secondarily, resulting in intermittent attacks of obstruction. When the volvulus unfolded itself, the symptoms ceased, only to return when the mass of small intestines became twisted on itself, and on account of adhesions, closed the duodenum also.

Waugh $^{43}$ (1928). Boy, aged $7 \frac{1}{2}$ years. There was a history of severe pain and vomiting since infancy. At operation a cysticocolic membrane passing over the second part of the duodenum to end on the hepatic flexure of the colon caused tight constriction of the duodenum. In addition a tendency towards arterio-mesenteric ileus was found. The band was divided and the ileus was left untreated. Although it was felt that possibly further treatment might be necessary for this, the patient did well without a second operation.

Judd and White ${ }^{44}$ (1929). CASE 1. Male, aged 19 years. Was well until 2 years of age, when attacks of gereralized abdominal pain began, recurring every 2 or 3 weeks. Pain occurred very soon after food, and was frequently associated with vomiting, from a few minutes to several hours after food, which always afforded relief. Appendix found on the left side and was removed without relief. $\mathrm{X}$-ray examination of the stomach was negative. Operation revealed 'chronic intestinal olstruction due to congenital malformation of the small intestine apparently at the duodeno-jejunal angle. The duodenum was dilated to about three times normal size ; the distal half was completely covered with peritoneum and possessed a short mesentery. There was a very firm band $7.5 \mathrm{~cm}$. wide extending from the root of the mesentery across the duodenojejunal flexure and becoming continuous with the posterior leaf of the transverse mesocolon. This band held the bowel fixed at this point and produced partial occlusion. The root of the mesentery, irstead of having its normal attachment to the posterior abdominal wall . . . seemed 
to be attached to a limited area anterior to the 2nd lumbar vertebra, being pedunculated, as it were. . . . The cæcum and ascending colon possessed an abnormally long mesentery, thus allowing for motion of that part of the bowel. The peritoneal band was separated, freeing parts, but not releasing the obstruction entirely. Therefore a lateral anastomosis was made between the duodenum and the loop of jejunum just below the point of obstruction.' Patient reported well 12 months later.

CASE 2. Female, age 19 years. Since she could remember she had had attacks of pain in the umbilical region, worse after meals, relieved by vomiting, and lasting 7 to 10 days. Up to 17 these recurred about twice a year; since then every 2 months. $X$-ray of the stomach and colon was negative. Operation revealed the duodenum 'distended and hypertrophied : it did not rotate up behind the stomach but came directly and obliquely downward and was compressed over the vertebræ by the weight of the mesentery of the small intestine. Instead of presenting on the left side of the vertebræ, the jejunum began in front and on the right side of the vertebræ. The peritoneal fold was divided in order to give a larger opening as the retroperitoneal portion of the duodenum became the jejunum. It was felt that the liberation of the constricting bands was sufficient to relieve the partial obstruction, though duodeno-jejunostomy might be necessary later. The immediate post-operative convalescence was uneventful, but the ultimate results were only fairly satisfactory.'

Foucar ${ }^{42}$ (1923). Boy, aged 18 months. Weight at birth $=8 \mathrm{lb}$. He had suffered from attacks of vomiting since birth except from the 3rd to the 5th month. The vomiting occurred $1 \frac{1}{2}$ to 2 hours after food and was projectile. Vomitus consisted of greenish yellow fluid containing very little food, but occasionally food given 6 hours previously would be brought up. For 12 months the child's weight had been stationary, attacks of vomiting occurring every week, and lasting one or two days. For the past 8 months the parents had noticed wave-like movements crossing the abdomen during the attacks. The presence of gastric peristalsis on the days of vomiting was confirmed by the author. An X-ray examination, made during a quiescent interval, did not reveal any obstruction. At operation 'the mesentery of the small intestine was found to be markedly œdematous, but the pylorus appeared normal. The thickening of the mesentery was due to marked enlargement of the mesenteric glands. Neither bands of adhesions nor obstruction were found. The appendix was removed and also a mesenteric gland .... The mechanism of this case would seem to be transitory obstruction due to inability of the intestines to adjust themselves because of the thickened œdematous mesentery.' 